\title{
Temporal Structure of Neuronal Activity among Cortical Neuron Subtypes during Slow Oscillations in Anesthetized Rats
}

\author{
Mika Ushimaru ${ }^{1,3}$ and $\odot$ Yasuo Kawaguchi ${ }^{1,2,3}$ \\ ${ }^{1}$ Division of Cerebral Circuitry, National Institute for Physiological Sciences, Okazaki 444-8787, Japan, ${ }^{2}$ Department of Physiological Sciences, SOKENDAI \\ (Graduate University for Advanced Studies), Okazaki 444-8787, Japan, and ${ }^{3} J a p a n$ Science and Technology Agency, Core Research for Evolutional Science \\ and Technology, Tokyo 102-0076, Japan
}

Slow-wave oscillations, the predominant brain rhythm during sleep, are composed of Up/Down cycles. Depolarizing Up-states involve activity in layer 5 (L5) of the neocortex, but it is unknown how diverse subtypes of neurons within L5 participate in generating and maintaining Up-states. Here we compare the in vivo firing patterns of corticopontine (CPn) pyramidal cells, crossed-corticostriatal (CCS) pyramidal cells, and fast-spiking (FS) GABAergic neurons in the rat frontal cortex, with those of thalamocortical neurons during Up/ Down cycles in the anesthetized condition. During the transition from Down- to Up-states, increased activity in these neurons was highly temporally structured, with spiking occurring first in thalamocortical neurons, followed by cortical FS cells, CCS cells, and, finally, CPn cells. Activity in some FS, CCS, and CPn neurons occurred in phase with Up-nested gamma rhythms, with FS neurons showing phase delay relative to pyramidal neurons. These results suggest that thalamic and cortical pyramidal neurons are activated in a specific temporal sequence during Up/Down cycles, but cortical pyramidal cells are activated at a similar gamma phase. In addition to Up-state firing specificity, CCS and CPn cells exhibited differences in activity during cortical desynchronization, further indicating projection- and state-dependent information processing within L5.

Key words: corticopontine cell; corticostriatal cell; fast spiking cell; frontal cortex; pyramidal cell; slow oscillation

\section{Significance Statement}

Patterned activity in neocortical electroencephalograms, including slow waves and gamma oscillations, is thought to reflect the organized activity of neocortical neurons that comprises many specialized neuron subtypes. We found that the timing of action potentials during slow waves in individual cortical neurons was correlated with their laminar positions and axonal targets. Within gamma cycles nested in the slow-wave depolarization, cortical pyramidal cells fired earlier than did interneurons. At the start of slow-wave depolarizations, activity in thalamic neurons receiving inhibition from the basal ganglia occurred earlier than activity in cortical neurons. Together, these findings reveal a temporally ordered pattern of output from diverse neuron subtypes in the frontal cortex and related thalamic nuclei during neocortical oscillations.

\section{Introduction}

The neocortex exhibits two major activity states: a slow-wave (SW) state in which neurons fluctuate between hyperpolarized

Received Dec. 14, 2014; revised July 22, 2015; accepted July 23, 2015.

Author contributions: M.U. and Y.K. designed research; M.U. performed research; M.U. and Y.K. analyzed data; M.U. and Y.K. wrote the paper.

This work was supported by Japan Science and Technology Agency, Core Research for Evolutional Science and Technology, and Grant-in-Aids for Scientific Research from the Ministry of Education, Culture, Sports, Science, and Technology/Japan Society for the Promotion of Science (KAKENHI No. 25250005, 25123723, 26120730, and 15H01456). We thank Allan T. Gulledge, Fuyuki Karube, and Yoshifumi Ueta for comments on the manuscript.

Correspondence should be addressed to: Yasuo Kawaguchi, Division of Cerebral Circuitry, National Institute for Physiological Sciences, Okazaki 444-8787, Japan. E-mail: yasuo@nips.ac.jp.

DOI:10.1523/JNEUROSCI.5074-14.2015

Copyright $\odot 2015$ the authors $\quad 0270-6474 / 15 / 3511988-14 \$ 15.00 / 0$
"Down-states" and depolarized "Up-states" occurring at low frequencies, and a continuously depolarized state [desynchronized (DS)-state; Metherate and Ashe, 1993; Steriade et al., 1993; Cowan and Wilson, 1994]. Gamma-band (30-80 Hz) oscillations are nested within Up-states (Valencia et al., 2013), and GABAergic fast-spiking (FS) cells are essential for their generation (Buzsáki and Draguhn, 2004; Sohal et al., 2009). During SWs, the strengths of synaptic connections are modified to restructure cortical circuits in response to previous experiences occurring during awake states (Louie and Wilson, 2001; Euston et al., 2007). For this synaptic modification to occur, the neocortex is thought to interact with multiple memory subsystems within the hippocampus, basal ganglia, and cerebellum. Up-states in 
A

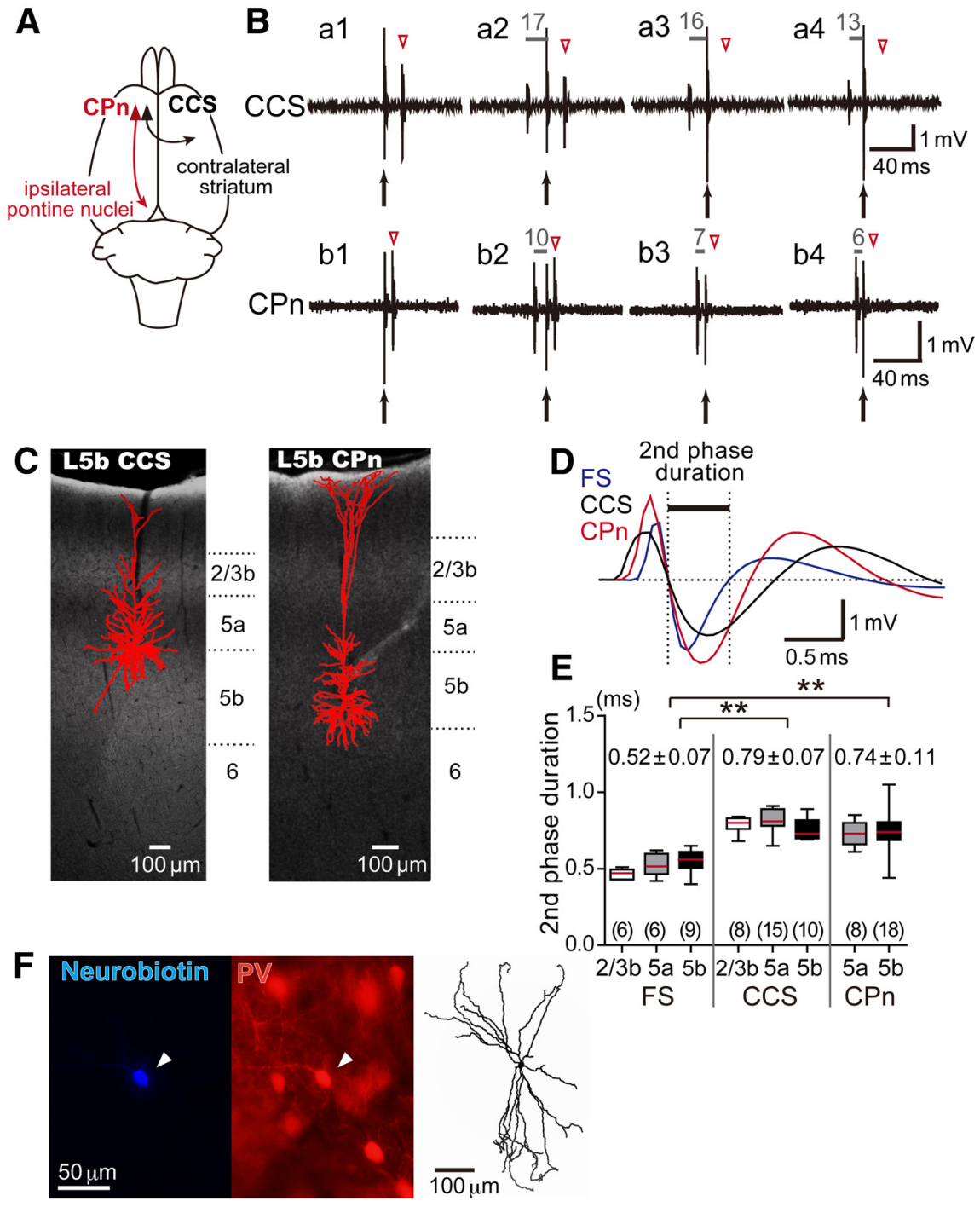

Figure 1. Identification of $\mathrm{CCS}, \mathrm{CPn}$, and FS cells in the rat frontal cortex. $\boldsymbol{A}$, Axonal projection sites for CCS and CPn cells. $\boldsymbol{B}$, Antidromic stimulation was used to identify CCS (a1-a4) and CPn (b1-b4) cells. In the case of an example CCS cell, spikes were induced at constant latency ( $16 \mathrm{~ms}$ ) by electrical stimulation of the contralateral striatum (red arrowheads; $\boldsymbol{a} 1, \boldsymbol{a} 2$ ). Spontaneous spikes preceding stimulation suppressed stimulus-induced spikes when their intervals were shorter than $16 \mathrm{~ms}(\boldsymbol{a} \mathbf{3}, \boldsymbol{a} 4)$. In the case of an example (Pn cell, latency for spike induction was $7 \mathrm{~ms}$ (red arrowheads; $\boldsymbol{b} 1, \boldsymbol{b} 2)$. Similarly, when the stimulation interval was $<7 \mathrm{~ms}$, spike was suppressed $(\boldsymbol{b} 3, \boldsymbol{b} 4)$. C, Morphologies of CCS (left) and CPn (right) cells recorded in layer 5 b. Sublayers 2/3b, $5 a$, and $5 b$ were identified on the basis of VGluT2 fluorescence immunohistochemistry (shown in grayscale). $\boldsymbol{D}$, Unit spike waveforms of CCS, CPn, and FS cells. Duration of negativity (second phase) following the first positivity was measured. $\boldsymbol{E}$, Spike durations (second negative phase) were shorter in FS cells than in either CCS or CPn cells across all sublayers. Cell numbers are given in parentheses. $F$, PV immunoreactivity of an FS cell (left), and its nonpyramidal dendritic pattern (right). Arrowheads, soma stained intracellularly with Neurobiotin and positive for PV.

SWs are thought to be initiated by activity in layer 5 (L5) pyramidal cells (Sanchez-Vives and McCormick, 2000; Chauvette et al., 2010; Lőrincz et al., 2015), but thalamic activity may also contribute to the SW generation (Crunelli and Hughes, 2010; David et al., 2013; Lemieux et al., 2014). Previously, we found that cells in various thalamic nuclei are diverse in their preferred timing of action potential generation during Up/Down cycles (Ushimaru et al., 2012); neurons in thalamic nuclei receiving input from the basal ganglia, and neurons in the reticular (Rt) nucleus, exhibit increases in activity during the transition from Down- to Up-states, while those receiving input from the cerebellum exhibit more temporally distributed activity.

In the frontal cortex, L5 pyramidal cells comprise multiple subtypes that can be segregated by their external projections. One prominent subtype, corticopontine (CPn) neurons, issues collaterals to the ipsilateral striatum (the input nucleus of the basal ganglia) and pontine nuclei, which provide innervation to the cerebellum. Crossed-corticostriatal (CCS) cells, which innervate both sides of the striatum (Wilson, 1987; Lei et al., 2004), are another prominent subtype of L5 pyramidal neuron. Because the firing patterns in thalamic nuclei receiving cerebellar or basal ganglia outputs differ during the SW- and DS-states, we hypothesized that similar state-dependent differences in firing patterns may also exist in CCS and CPn cells, which might temporally segregate cortical output to basal ganglia and cerebellar memory subsystems. Furthermore, CCS and $\mathrm{CPn}$ cells can be differentiated according to their cortical depth, and their projections to the parahippocampal areas, or the spinal cord, correspondingly differ between sublayers (Morishima and Kawaguchi, 2006; Hirai et al., 2012; Ueta et al., 2014). Therefore, it is possible that the firing characteristics of CCS and CPn neurons during SW- and DS-states vary across sublayers.

In this study, we compared firing patterns during SW- and DS-states in CCS, $\mathrm{CPn}$, and FS cells across several cortical sublayers that are differentially targeted by thalamic afferents (Shigematsu et al., 2015), and compared these patterns with those of neurons in thalamic nuclei investigated previously (Ushimaru et al., 2012). We identified temporally ordered patterns of activation of these subtype- and sublayer-specific neuronal populations during SW oscillations in an anesthetized condition.

\section{Materials and Methods}

Electrophysiology: single-unit and local field potential recordings and electrical stimulation. All experiments were performed in accordance with the guidelines of the Institutional Animal Care and Use Committee of the National Institutes of Natural Sciences. Male Wistar rats (5 weeks old) were anesthetized with chloral hydrate (initial dose, $400 \mathrm{mg} / \mathrm{kg}$, i.p.; supplemental doses of $80 \mathrm{mg} / \mathrm{kg}$ were given intravenously through the femoral vein) and fixed on a stereotaxic frame. Body temperature was maintained at $37^{\circ} \mathrm{C}$ throughout the experiment with a heating pad.

Electrophysiological data were acquired using Axoclamp 2B amplifiers (Molecular Devices) and Spike2 software (Cambridge Electronic Devices). Two electrodes were placed in the vicinity of the secondary motor area (rostral medial agranular cortex; $2.7-3.7 \mathrm{~mm}$ anterior to bregma; $1.3-1.9 \mathrm{~mm}$ lateral to the midline; depth, $0.6-2 \mathrm{~mm}$ ). One glass pipette filled with $0.5 \mathrm{M} \mathrm{NaCl}$ or $0.5 \mathrm{M} \mathrm{KCl}$ containing $2 \%$ Neurobiotin (w/v; Vector Laboratories; resistance, 20-40 M $\Omega$ ) was used for single-unit recording. Voltage during unit recordings was filtered on-line at $0.3-3$ $\mathrm{kHz}$ and was sampled at $16 \mathrm{kHz}$. The other glass pipette was used for local field potential (LFP) recording; it was filled with $2 \mathrm{M} \mathrm{NaCl}$ (resistance, 15-25 M $\Omega$ ) and was placed in L5b. Potentials for LFP recording were 
filtered on-line at $0.1-200 \mathrm{~Hz}$ and were sampled at $1200 \mathrm{~Hz}$. We obtained LFPs without extracellular unit spikes. The distance from the L5b LFP recording electrodes to the unit recording electrode was $1378 \pm 378 \mu \mathrm{m}$ for L2/3b cells $(n=13), 988 \pm 283 \mu \mathrm{m}$ for L5a cells $(n=27)$, and $776 \pm 333 \mu \mathrm{m}$ for L5b cells ( $n=33$; measured in fixed sections; see below). In these configurations, raw field potentials are well correlated, and Up start/end times are synchronized between the two electrodes (Ushimaru et al., 2012).

To identify CCS and CPn cells, bipolar stimulating electrodes were stereotaxically implanted in the contralateral striatum $(0.5 \mathrm{~mm}$ anterior to bregma; $3.0 \mathrm{~mm}$ lateral to the midline; depth, $4.5 \mathrm{~mm}$ ) and ipsilateral pontine nuclei $(6.2 \mathrm{~mm}$ posterior to bregma; $0.7 \mathrm{~mm}$ lateral to the midline; depth, $9.3 \mathrm{~mm}$ ) in each animal. Stimulating electrodes consisted of two stainless steel enamel-coated wires (sizes, 0.005 BF; stainless steel 304, H-ML, H-ML/ML bifilar; California Fine Wire). For stimulation, monophasic square-wave pulses (duration, 0.2 $\mathrm{ms}$; intensity, $0.1-1 \mathrm{~mA}$ ) were applied at $1 \mathrm{~Hz}$. Correct positioning of stimulation electrodes was confirmed in fixed sections obtained from the perfused brain.

Animal movements and LFPs recorded in the cortex were carefully monitored to determine the anesthetic condition. At the end of the anesthetic level cycle, we recorded a period of 10-20 s during which the animals showed no signs of consciousness, despite having desynchronized LFPs (indicated by a cessation of SWs). A supplemental dose of the anesthetic was given after the DS-state recording.

Neuron labeling, immunohistochemistry, and

histology. At the end of each recording, the recorded neurons were labeled by juxtacellular injection of Neurobiotin using a cyclic application of positive current pulses (one cycle, $600 \mathrm{~ms} ; 250 \mathrm{~ms}$ on/350 ms off; $1-8 \mathrm{nA}$; 5-15 min; Pinault, 1996; Ushimaru et al., 2012). The site of LFP recording with another $2 \mathrm{M} \mathrm{NaCl}$-filled electrode was marked by coagulation using positive current pulses (cycle, $7 \mathrm{~s}$ on/off; intensity, $10 \mu \mathrm{A}$; duration, $1-2 \mathrm{~min})$.

One to two hours after injection, rats were perfused through the heart with a prefixative solution $\left[250 \mathrm{~mm}\right.$ sucrose and $5 \mathrm{mM} \mathrm{MgCl}_{2}$ in a $0.02 \mathrm{M}$ phosphate-buffered (PB) solution], followed by $300 \mathrm{ml}$ of fixative containing $4 \%$ paraformaldehyde, $0.05 \%$ glutaraldehyde, and $0.2 \%$ picric acid in $0.1 \mathrm{M}$ PB solution. One hour after perfusion, the brain was removed and kept in the same fixative overnight.

The fixed brains were cut into $50-\mu \mathrm{m}$-thick sections. For FS cells, sections were incubated with Alexa Fluor 350-conjugated streptavidin (1:200 or 1:500; S11249, Life Technologies) in $0.05 \mathrm{M}$ Tris-buffered saline (TBS) with $0.5 \%$ Triton X-100 (TX) for $1 \mathrm{~h}$ at room temperature. After washing with TBS, sections that contained recorded cells were incubated with a mouse antibody against parvalbumin (PV; 1:3000; P-3171, SigmaAldrich) in TBS containing 10\% normal goat serum, 2\% bovine serum albumin, and $0.5 \%$ TX in TBS overnight at $4^{\circ} \mathrm{C}$. Sections were then incubated with an Alexa Fluor 594-conjugated secondary antibody. To identify cortical sublayers (Morishima et al., 2011; Ushimaru et al., 2012), sections adjacent to the soma were incubated with a guinea pig antibody against vesicular glutamate transporter type 2 (VGluT2; 1:2000; AB2251, EMD Millipore) in TBS containing 10\% normal goat serum, $2 \%$ bovine serum albumin, and $0.1 \%$ TX in TBS overnight at $4^{\circ} \mathrm{C}$. Sections were then incubated with an Alexa Fluor 594-conjugated secondary antibody. After sublayer identification of recorded cells, the sections were incubated with avidin-biotin-peroxidase complex (1:100; Vector Laboratories) in $0.05 \mathrm{M}$ TBS with $0.1-0.5 \% \mathrm{TX}$ overnight at $4^{\circ} \mathrm{C}$. After washing in TBS, the slices were reacted with diaminobenzidine (DAB; $0.02 \%$ ), nickel ammonium sulfate $(0.3 \%)$, and $\mathrm{H}_{2} \mathrm{O}_{2}(0.01 \%)$ in Tris- $\mathrm{HCl}$ buffer.

For CCS and CPn cells, labeled neurons were visualized using the avidin-biotin-peroxidase complex and the DAB reaction. Next, sublayers were identified by VGluT2 immunoreactivity, as described above.

In some sections, with the LFP recording site we performed fluorescence immunohistochemistry for the neurofilament heavy chain (NF-H) to confirm that the recording area was M2 (Ueta et al., 2014). The sections were incubated overnight with a mouse monoclonal antibody against NF-H (N-200 antibody, 1:1000; N0142, Sigma-Aldrich) and a guinea pig antibody against VGluT2, followed by incubation with Alexa Fluor 488- and Alexa Fluor 594-conjugated secondary antibodies, respectively.

After the immunohistochemical procedures, sections containing the recorded cell were post-fixed in $1 \% \mathrm{OsO}_{4}$ in $0.1 \mathrm{M} \mathrm{PB}$ containing $7 \%$ glucose, dehydrated, and flat embedded on glass slides in Epon. Stained neurons were drawn using a $60 \times$ or $100 \times$ oil-immersion objective with additional $1.25 \times$ magnification and reconstructed three-dimensionally using the Neurolucida system (MBF Bioscience).

Data analysis. Burst-firing strength was quantified by calculating the burst ratio (number of spikes discharged within $10 \mathrm{~ms}$ interval/total spike number; see Fig. 2C). Up-states were detected using a method described by Mukovski et al. (2007). Briefly, the $20-100 \mathrm{~Hz}$ band of the LFP was extracted, and durations with a high SD in this bandwidth were defined as Up-states. If two Up-states or two Down-states were separated by an interval of $<40 \mathrm{~ms}$, the two states were extended to fill the gap and pasted together (Volgushev et al., 2006). Up-/Down-state border crossings for periods $<40 \mathrm{~ms}$ were not considered as state shifts. To quantify the timing of firing in Up-states, we normalized each Up duration to 1 $(-0.5$ to 0.5 ; see Fig. 3$)$. To evaluate firing time specificity in each cell, the $\chi^{2}$ test for goodness of fit was used. $\chi^{2}$ values were calculated as $\Sigma[\text { (observed - expected })^{2} /$ expected $]$, where "observed" is the spike number in each bin, and "expected" is the average spike number. 
A
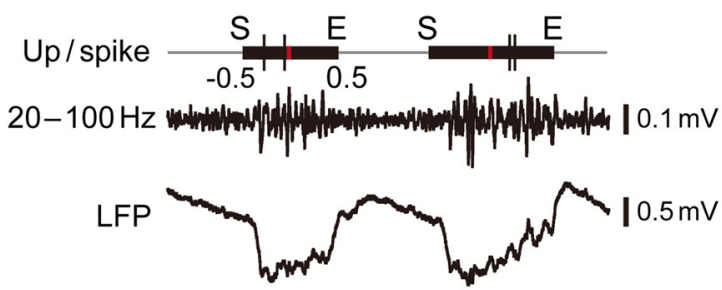

Unit

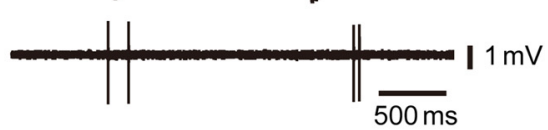

B
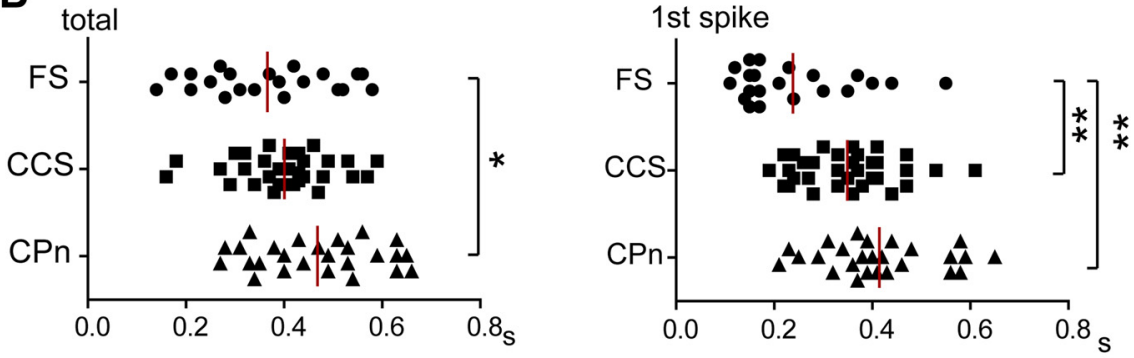

C total $\quad 0^{\text {chi square }}$
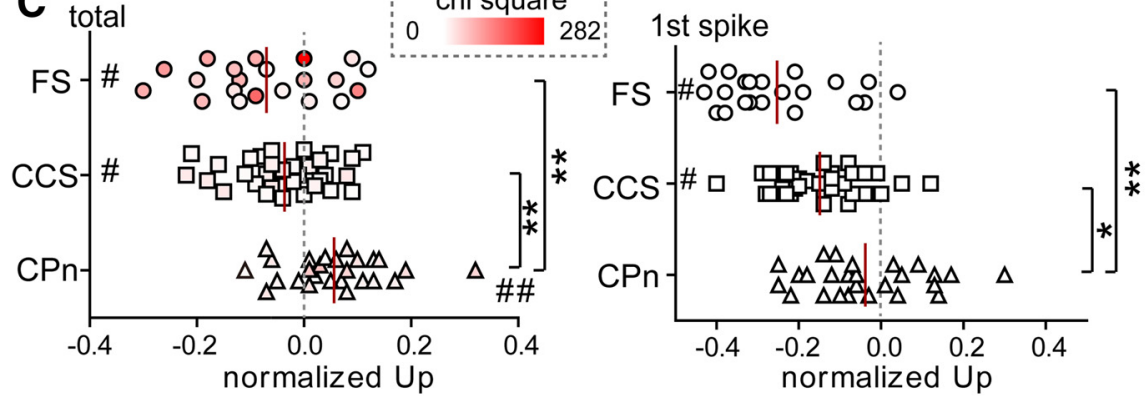

D
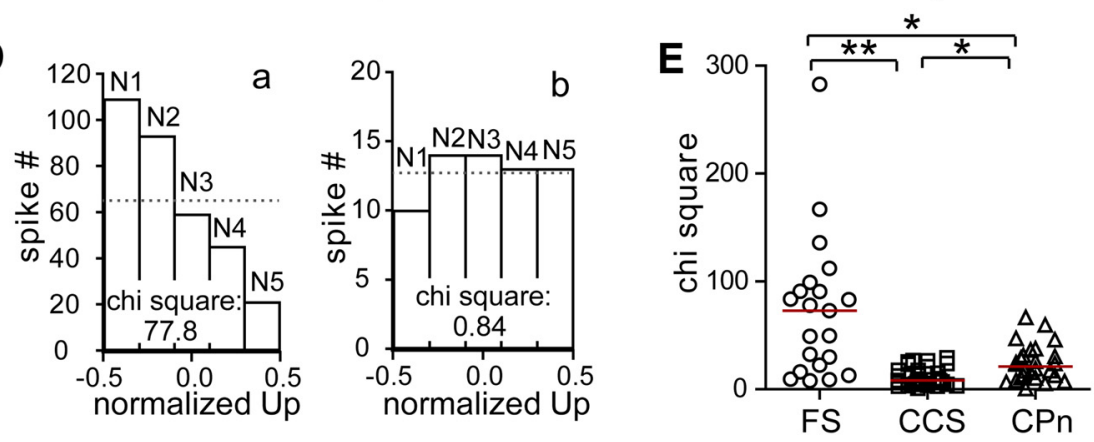

Figure 3. Cell type-dependent firing specificity during Up-states. A, Examples of Up-states detected from the LFP and the simultaneously recorded unit activity of an FS cell. Large deviations in the $20-100 \mathrm{~Hz}$ component of the LFP were used to detect Up-states. S, Start of Up-state; E, end of Up-state. B, Left, Medians of actual firing times measured from Up start in individual cells. FS cells fired earlier than CPn cells ( ${ }^{*} p<0.05$, post hoc Dunn test). Right, Medians of actual firing times of first spikes measured from Up start during each Up-state in individual cells. First spike timings were earlier in FS cells than in CCS or CPn cells $\left({ }^{* *} p<0.01\right)$. C, Left, medians of normalized firing times of all Up spikes in individual cells. FS and CCS cells tended to exhibit peak firing during the early Up-state (\#p $<0.05$, one-sample $t$ test), whereas (Pn cells tended to exhibit peak firing in the late Up-state (\#\#p <0.01). FS and CCS cells fired earlier than CPn cells (**p $<0.01$, post hoc Dunn test), with FS cells having higher $\chi^{2}$ values (color-coded scale; see $D$ for $\chi^{2}$ values). Right, Medians of first spike timings in normalized Up-states for individual cells. MostFS and CCS cells showed first spikes in the early Up-state (\#p $<0.05$, one-sample t test). First spike timings were earlier in FS cells than in CPn cells $\left({ }^{* *} p<0.01\right)$, and earlier in CCS cells than in CPncells ( $\left.{ }^{*} p<0.05\right)$. D, Spike distributions in five divisions of the Up-state and their $\chi^{2}$ values. $\boldsymbol{D a}$, Early Up firing of an FS cell. $\boldsymbol{D b}$, Temporally uniform firing of a CCS cell during Up-states. Dotted line, Mean spike number. $\boldsymbol{E}, \chi^{2}$ value differences among three groups $(p<0.01) \cdot \chi^{2}$ values of FS cells were larger than those of $\mathrm{CCS}$ or CPn cells $\left({ }^{* *} p<0.01,{ }^{*} p<0.05\right.$, respectively), and values of $\left(P n\right.$ cells were larger than those of CCS cells $\left({ }^{*} p<0.05\right)$. Horizontal red lines indicate median values.

spike timing relative to gamma troughs for each cell, and the significance of firing modulation was assessed using the Rayleigh test (see Fig. 6). Neurons with $>90$ spikes were used for this analysis. We computed the mean angle and the angular concentration $r$, which was the length of the mean vector of all phase angles normalized by the number of spikes/angle from the phase histograms. To compare the modulated phase angle, a multisample Watson-Williams test was used. To detect the distribution uniformity of modulated angles in each neuron subtype, the Hodges-Ajne test for circular uniformity was used. To quantify the firing frequency change from the Up-state in the SW- to DSstate, the DS preference for firing was defined as (DSf $-\mathrm{Upf}) /(\mathrm{DSf}+\mathrm{Upf})$, where DSf is the firing frequency in the DS-state and Upf is the firing frequency in the Up-state in the SW (see Fig. 8).

Basic statistical analysis was performed using Prism (GraphPad Software). Circular statistics and LFP processing (to detect the Upstate start/end) were computed in MATLAB (MathWorks). Data are expressed as the mean \pm SD. Statistical significance was set at a 95\% confidence level (two-tailed). The KruskalWallis test was used to confirm significant differences among subtypes in individual parameters, followed by a post hoc Dunn test. For comparison of two cell classes, the MannWhitney $U$ test and the $\chi^{2}$ test were used.

\section{Results}

Identification of recorded neuron types Two separate projection subtypes of pyramidal cells, CCS and CPn cells, were identified by antidromic firing induced by electrical stimulation of their projection sites (Fig. $1 A, B$ ). CCS cells were identified by antidromic firing following contralateral striatum stimulation (Fig. $1 B$, top; antidromic latency: $18 \pm 5 \mathrm{~ms}, n=33)$. CPn cells antidromically fired following ipsilateral pontine stimulation (antidromic latency: $6 \pm 3 \mathrm{~ms}, n=26$; Fig. $1 B$, bottom).

In the rat frontal agranular cortex, $\mathrm{L} 2 / 3$ and $\mathrm{L} 5$ can each be divided into two sublayers, L2/3a and L2/3b, and L5a and L5b (Morishima et al., 2011; see Materials and Methods). Compared with the more superficial "a" layers, L2/3b and L5b have denser immunoreactivity for the VGluT2 (Fig. 1C) and are considered to be a more significant thalamic input-recipient zone. After recording unit activity, we labeled recorded neurons with juxtacellular injection of Neurobiotin. The laminar positions of labeled neurons (L2/3b, L5a, and L5b) were identified by VGluT2 immunohistochemistry (Fig. 1C).

Units that were not antidromically activated, had narrower spike widths (Fig. 1D), and a nonpyramidal dendritic shape (Fig.

Gamma $(30-80 \mathrm{~Hz})$ bands in the LFP were digitally filtered in Spike2, and large troughs that were more than threefold the root mean square amplitude of those in Down-state duration were detected (see Figs. 5, 6, 7). Detected gamma troughs were defined as $0^{\circ}$ in the cycle. We made phase histograms $\left(20^{\circ} \mathrm{bin}\right)$ of
$1 F$, right) were classified as FS cells, as these cells were frequently positive for parvalbumin (15 of 21 cells tested; Fig. $1 F$, left). The second phase of unit waveforms, which deflected in the negative 
A

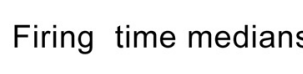
normalized Up

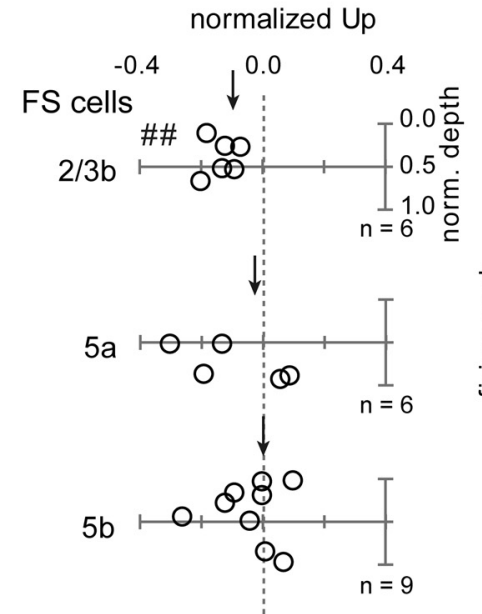

B

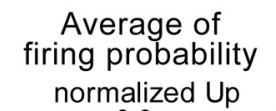

\section{Total spike distribution}

0.5
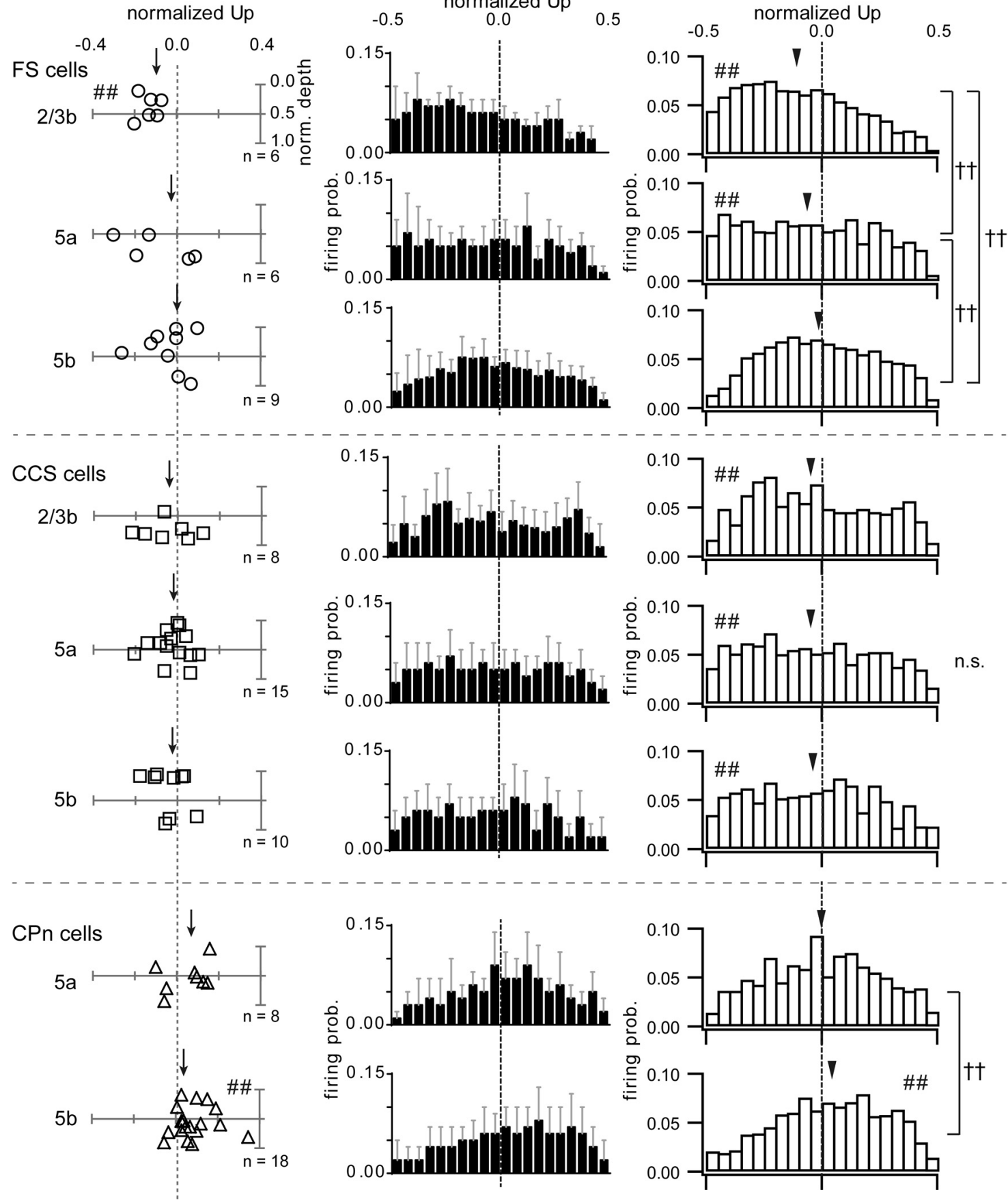

Figure 4. Temporal specificity of unit firing during Up-states among neuronal subtypes and sublayers. $A$, Up firing times of FS, CCS, and CPn cells in individual sublayers. The thickness of each sublayer was normalized to 1. Arrows, Medians of firing time. L2/3b FS cells fired earlier than L5b CPn cells $(p<0.01$, posthoc Dunn test). Almost all L2/3b FS cells preferentially fired spikes in the firsthalf of Up-states (\#\#p $<$ 0.01, one-sample t test), while L5b CPn cells fired more preferentially in the latter half of Up-states (\#\# $<0.01)$. B Average firing probability during Up-states in individual subtypes. Error bars indicate SDs. The number of spikes (mean \pm SD) are as follows: FS cells, $411 \pm 347$ in L2/3b ( $n=6$ cells), $217 \pm 115$ in L5a ( $n=6)$, and $466 \pm 664$ in L5b ( $n=9)$; CCS cells, $80 \pm 52$ in L2/3b ( $n=8), 98 \pm 71$ in L5a ( $n=$ 15), and $70 \pm 18$ in L5b $(n=10)$; $(P n$ cells, $100 \pm 62$ in L5a $(n=8)$, and $97 \pm 64 \mathrm{in} L 5 b(n=18)$. C, Total spike distribution of FS, CCS, and CPn cell spikes during Up-states in individual sublayers. FS and CPn cells, but notCCScells, were different in spike timebetween sublayers ( $+\nmid p<0.01$; posthocDunn testforFS andCCS, and Mann-Whitney Utestfor CPn cells). FS cells in L2/3b and L5a, andCCS cells in all sublayers had biased spike distributions toward the early Up-state (\#\# $<0.01$, one-sample t test), whereas L5b CPn cells had biased spike distributions toward the late Up-state (\#\#p $<0.01$ ). Arrowheads, Medians of Up spike time in each subgroup.

direction, was narrower in FS cells $(0.52 \pm 0.07 \mathrm{~ms}, n=21)$ than in CCS cells $(0.79 \pm 0.07 \mathrm{~ms}, n=33)$ or CPn cells $(0.74 \pm 0.11 \mathrm{~ms}, n=$ $26 ; p<0.01$, post hoc Dunn test; Fig. $1 D, E)$. In the following sections, we compare unit activity in these neuron subtypes in each sublayer during SW- and DS-states.
Burst-firing patterns differ among cell subtypes

Cortical neurons fired mostly during Up-states [ratio of spike number in Down-states to that in whole SW-states: $0.02 \pm 0.03$ in FS cells $(n=21) ; 0.03 \pm 0.05$ in CCS cells $(n=33)$; and $0.01 \pm$ 0.02 in CPn cells $(n=26)]$. To characterize the firing patterns of 
individual subtypes in Up-states during SW, we investigated the instantaneous interspike intervals (ISIs) in FS, CCS, and CPn cells. Some CPn cells showed skewed ISI distributions with earlier peaks ( $\sim 10 \mathrm{~ms}$; Fig, $2 A c)$, whereas the ISI distributions of CCS and FS cells were less skewed and had later peaks (Fig. 2Aa,b). Medians of ISI values $<200 \mathrm{~ms}$ were smaller in CPn cells ( $28 \pm 11$ $\mathrm{ms}$ ) than in CCS cells ( $43 \pm 20 \mathrm{~ms}$ ) or FS cells ( $40 \pm 11 \mathrm{~ms} ; p<$ 0.05 ; Fig. $2 B$ ). The bursting spike ratio (ratio of spikes fired within a $10 \mathrm{~ms}$ interval to total spike number) in CPn cells was higher than that in both CCS and FS cells ( $p<0.01$; Fig. $2 C$ ). Thus, burst patterns differed not only between pyramidal and FS cells, but also between pyramidal cell subtypes.

\section{Temporal specificity of Up-state firing in cortical cells in individual sublayers}

To study temporal firing specificity in each subtype, we quantified the firing time of individual spikes during Up-states (Fig. $3 A$ ). First, we confirmed that Up-state durations used for individual analyses did not differ among the neuron subtypes and sublayers. On this basis, we found that the firing time during Up-states was different among the three subtypes $(p<0.05$, Kruskal-Wallis test), as follows: FS cells fired earlier (0.37 \pm $0.13 \mathrm{~s}$; time from start of Up-state) than CPn cells ( $0.47 \pm 0.12 \mathrm{~s}$; $p<0.05$, post hoc Dunn test; Fig. 3B, left; CCS cells, $0.40 \pm 0.10$ s). In particular, the first spike time during Up-states was different among the three subtypes ( $p<0.01$, Kruskal-Wallis test): FS cells fired earlier during Up-states $(0.24 \pm 0.12 \mathrm{~s})$ than both CCS cells $(0.35 \pm 0.10 \mathrm{~s})$ and CPn cells $(0.42 \pm 0.12 \mathrm{~s} ; p<0.01$, post hoc Dunn test; Fig. $3 B$, right).

Next, to quantify the relative timing of activity during Upstates, we normalized each Up-state duration, identified from the LFP in L5, to $1[-0.5$ (Up-state start) to 0.5 (Up-state end)] and obtained the normalized Up-state firing time for individual action potentials (Fig. 3A). FS and CCS cells preferentially fired spikes in the first half of Up-states [Fig. 3C, left; median Up-state firing time, -0.09 for FS cells $(p<0.05$, one-sample $t$ test) and -0.04 for CCS cells $(p<0.05)$ ], while CPn activity occurred preferentially in the latter half of Up-states (median, $0.05 ; p<$ $0.01)$. These relative Up-state firing times differed among subtypes (Fig. 3C, left; $p<0.01$, Kruskal-Wallis test): CPn cells fired later than FS and CCS cells ( $p<0.01$, post hoc Dunn test). The normalized Up firing time of first spikes also differed among the three subtypes (Fig. $3 C$, right, $p<0.01$; median, -0.29 for FS cells, -0.14 for CCS cells, and -0.07 for CPn cells).

Normalized firing times within Up-states were significantly correlated with real firing time during Up-states in each subtype (correlation coefficients were 0.86 in FS cells, 0.55 in CCS cells, and 0.52 in CPn cells; $p<0.01$ ) and for the first spike during the Up-state (correlation coefficients were 0.87 in FS cells, 0.62 in CCS cells, and 0.69 in CPn cells; $p<0.01$ ). Thus, each neuron showed distinct subtype-specific temporal preferences for action potential generation during Up-states.

To quantify the temporal distribution of activity during Upstates, we divided our normalized Up-states into five divisions and quantified the variance in spike distributions as $\chi^{2}$ values (Fig. 3D). Significance was tested using $\chi^{2}$ tests for goodness of fit (Ushimaru et al., 2012; see Materials and Methods). Higher $\chi^{2}$ values indicated larger variances in spike distributions among the five bins, suggesting a concentration of activity in specific Upstate subdivisions. $\chi^{2}$ values of $>9.49$ indicated uneven distributions ( $p<0.05$; see color coding in Fig. $3 C$ ). The $\chi^{2}$ values of FS cells $(73.0 \pm 65.7)$ were larger than for either of the pyramidal cell subpopulations ( $p<0.05$; Fig. $3 E$ ), while CPn cells had larger $\chi^{2}$
Table 1. Comparison of $\chi^{2}$ value (Up firing time preference) in each subtype

\begin{tabular}{|c|c|c|c|c|}
\hline & FS & CCS & CPn & $\begin{array}{l}\text { Dunn/MW } \\
\text { (CS test) }\end{array}$ \\
\hline$L 2 / 3 b$ & $80.2 \pm 52.7(5 / 6)$ & $12.4 \pm 8.9(4 / 8)$ & & $\mathrm{FS}>\mathrm{CCS}$ (n.s.) \\
\hline L5a & $48.2 \pm 31.0(5 / 6)$ & $10.3 \pm 9.2(5 / 15)$ & $21.8 \pm 12.3(7 / 8)$ & $\begin{array}{l}F S>C C S \\
\quad(F S>C C S, \\
\quad(P n>C C S)\end{array}$ \\
\hline L5b & $84.9 \pm 88.2(8 / 9)$ & $12.6 \pm 7.1(5 / 10)$ & $25.0 \pm 18.8(14 / 18)$ & $\mathrm{FS}>\mathrm{CCS}$ (n.s.) \\
\hline $\begin{array}{l}\text { Dunn/MW } \\
\text { (CS test) }\end{array}$ & n.s. (n.s.) & n.s. (n.s.) & n.s. (n.s.) & \\
\hline
\end{tabular}

Data are reported as the mean $\pm S D$ of $\chi^{2}$ values (cells with a value $>9.49(p<0.05) /$ total number of cells). Dunn Significant differences in post hoc Dunn multiple comparison test $(p<0.05)$; MW, significant difference in MannWhitney $U$ test $(p<0.05)$; $C$, significant difference in $\chi^{2}$ contingency test $(p<0.05)$.

values $(24.0 \pm 16.9)$ than CCS cells $(11.5 \pm 8.3 ; p<0.05$, post hoc Dunn test).

In addition to the neuron subtypes, we further compared Up firing times and $\chi^{2}$ values among different sublayers. Almost all L2/3b FS cells preferentially fired spikes in the first half of Upstates (Fig. $4 A ; p<0.01$, one-sample $t$ test), while L5b CPn cells more preferentially in the latter half of Up-states $(p<0.01)$. L2/3b FS cells fired earlier than L5b CPn cells (Fig. $4 A ; p<0.01$, post hoc Dunn test). FS cells fired preferentially in the earliest phase of the Up-state in L2/3b and in the early to middle phases in L5a and L5b (Fig. 4A, top). Furthermore, spike distributions of each subtype were compared among the sublayers (Fig. 4B,C). Spikes from L2/3b FS cells (normalized median, $-0.11 ; n=2465$ spikes) occurred earlier than those from L5a $(-0.06 ; n=1299)$ and L5b FS cells $(-0.01 ; n=4194$; Fig. $4 C$, top; $p<0.01$, post hoc Dunn test), and spikes from L5a FS cells occurred earlier than those from L5b cells $(p<0.01)$. CCS cells, on the other hand, fired preferentially in the early and middle phases of Up-states, regardless of their sublayer (Fig. $4 A$, middle). Total spike distributions in individual sublayers revealed similar firing times among L2/3b $(-0.05 ; n=638), \mathrm{L} 5 \mathrm{a}(-0.05 ; n=1463)$, and L5b CCS cells $(-0.04 ; n=695$; Kruskal-Wallis test; Fig. $4 C$, middle). However, L5b CPn cells $(0.04 ; n=1747)$ exhibited preferential firing during the late phase of Up-states (Fig. $4 A$, bottom), while L5a CPn cells $(0.00 ; n=800)$ were active earlier (Fig. $4 C$, bottom; $p<0.01$, Mann-Whitney $U$ test). Together, these results suggest that Up-state activities in FS and CPn neurons are cell type and sublayer dependent, with FS cells, especially those in superficial layers, firing earliest within Up-states.

On the other hand, $\chi^{2}$ values were relatively independent of the sublayer. In all sublayers, FS cells had higher $\chi^{2}$ values than CCS cells [ $p<0.01$, Mann-Whitney test in L2/3b, $p<0.01$ (L5a), and $p<0.05$ (L5b), post hoc Dunn test, respectively; Table 1], indicating more activity concentration in specific Up-state subdivisions. These imply a neuron subtype-dependent firing preference during the Up-state.

\section{Gamma firing phases differ among cell subtypes}

Gamma oscillations, which are more prominent during Upstates than during Down-states, may facilitate firing synchronization of cortical neurons (Steriade, 2006; Mena-Segovia et al., 2008; Puig et al., 2008). We obtained the gamma power in individual Up-states of $>170 \mathrm{~ms}$ (Up number, $34 \pm 2.6$; five recordings). Troughs of the gamma wave during Up-states were detected when the wave amplitude was threefold larger than the root mean square amplitude in Down-states. The gamma power correlated with the trough number during Up-states of those $>170 \mathrm{~ms}$ [Fig. $5 \mathrm{~A}$; correlation coefficient (c.c.) $=0.43 \pm 0.16$, $p<0.05$; four of five recordings]. The trough number correlated 

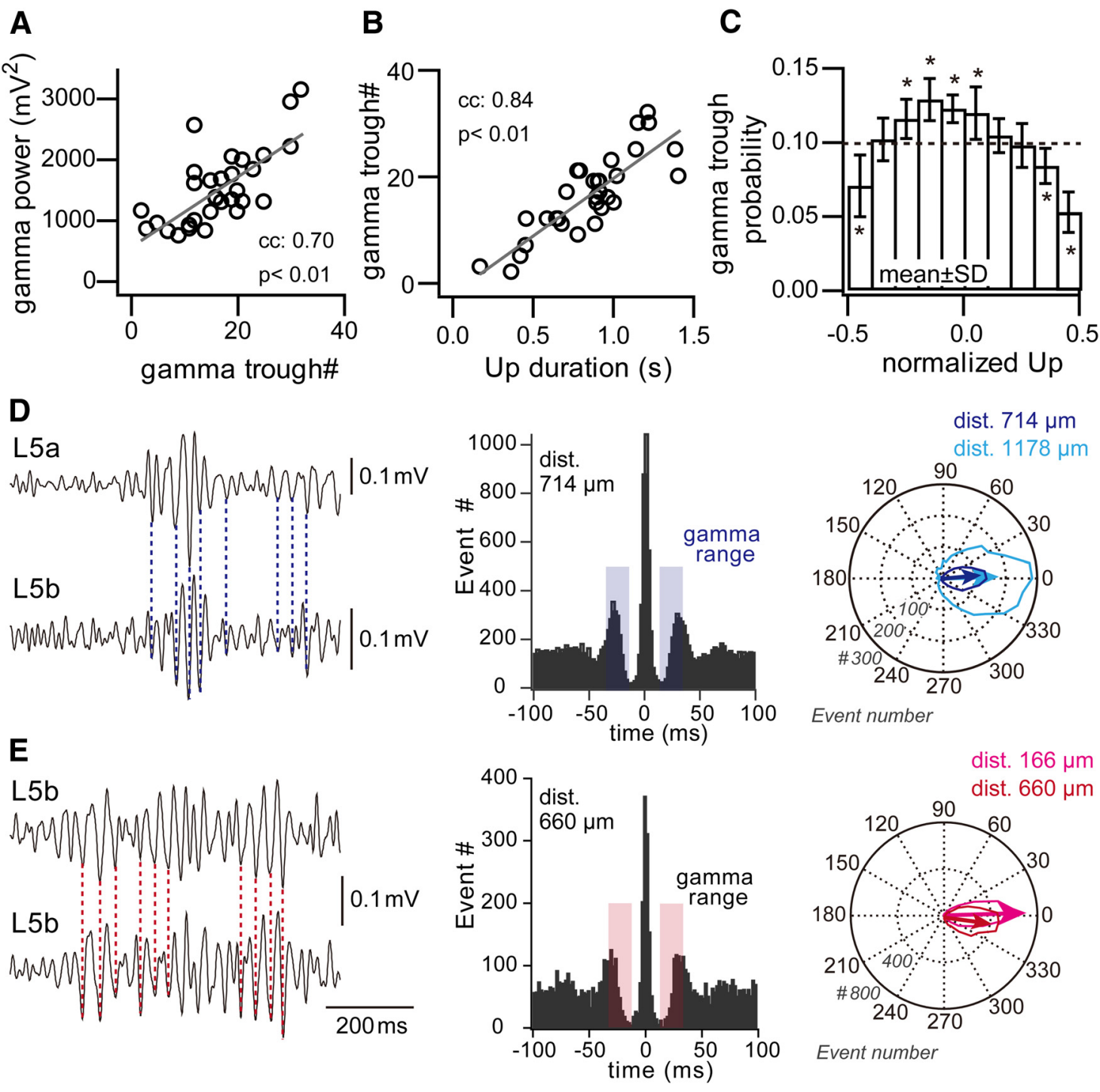

Figure 5. Gamma waves during Up-states and its synchronization within L5. $A$, Correlation between the gamma power and wave trough number during Up-states. $\boldsymbol{B}$, Correlation between the gamma trough number and Up-state duration. C, Distribution of gamma troughs in Up-states. Their probability was lower at the beginning and ending, and higher around the center of Up-states $\left({ }^{*} p<0.01\right.$, one-sample $t$ test assuming the uniform distribution during the Up-state). $\boldsymbol{D}$, Left, Gamma LFPs recorded from L5a and L5b sites [distance (dist.), $714 \mu \mathrm{m}$ ]. Wave correlation, 0.57 . Center, Cross-correlogram of trough timings at the two sites. The troughs of gamma waves were highly synchronized. Right, Phase relation of gamma-wave troughs (two pairs of recording, dark and light blue, respectively). Angular concentrations, 0.84 and 0.59 , respectively. Phase difference, $5.24^{\circ}$ and $1.80^{\circ}$, respectively. Colored contour, Distribution of phase lags between detected gamma troughs; gray italic number, event number; arrow, mean vector. $E$, Left, Gamma LFPs recorded from two L5b sites (distance, $660 \mu \mathrm{m}$ ). Wave correlation, 0.75 . Center, Cross-correlogram. Right, Phase relation (two pairs of recording, pink and red, respectively). Angular concentrations, 0.88 and 0.84 , respectively; phase difference, $1.74^{\circ}$ and $7.55^{\circ}$, respectively.

with the duration of all Up-states (c.c. $=0.87 \pm 0.07, p<0.01$; all five recordings). The distribution of gamma troughs was not uniform during Up-states and their occurrence was lower at the beginning and ending of Up-states (Fig. 5C).

We investigated whether gamma waves in the local field potential were temporally correlated between the sublayers (Fig. $5 D$ ) and between the horizontally distant sites within the same depth (Fig. $5 E$ ) of the frontal cortex. The troughs of gamma waves were synchronized between L5a and L5b (Fig. 5D; time difference, $-0.20 \pm 0.46 \mathrm{~ms}, n=3$ ), and between two sites within L5b (Fig. $5 E$; time difference, $-0.18 \pm 0.57 \mathrm{~ms}, n=3$ ), but were not stably correlated between L2/3b and L5b. These indicate that the gamma oscillations are synchronized at least within L5 (Destexhe et al., 1999).

We asked whether cortical subpopulations may show differential coupling of firing with the Up-state gamma rhythm. Therefore, we analyzed firing modulation of L5 cells by the gamma wave recorded at L5. Some FS, CCS, and CPn cells fired in a gamma-modulated manner (Fig. 6A, B). We quantified the normalized length (angular concentration) and mean angle of vectors using circular analysis $\left(0^{\circ}\right.$, negative trough of the gamma wave; see Materials and Methods). The angular concentration was not significantly different among the three neuronal subtypes $(0.17 \pm 0.07$ for FS cells, $0.14 \pm 0.07$ for CCS cells, and $0.14 \pm$ 0.10 for CPn cells). Cells with significant gamma modulation were identified by the Rayleigh test ( $p<0.05$; modulated cell number/total cell number; Fig. $6 C$ ). The modulated cell proportion was lower in CPn cells than in FS cells $\left(p<0.05, \chi^{2}\right.$ test $)$. The mean angular concentration of modulated cells (vectorial sum) was 0.17 for FS cells, 0.18 for CCS cells, and 0.15 for CPn cells. The mean angle of modulated cells was $355^{\circ}$ for FS cells, $287^{\circ}$ for CCS cells, and $313^{\circ}$ for CPn cells (Fig. $6 D$ ). The preferred firing phase was different among the three subtypes $(p<0.01$, threesample Watson-Williams test), with FS cells being different from 
A
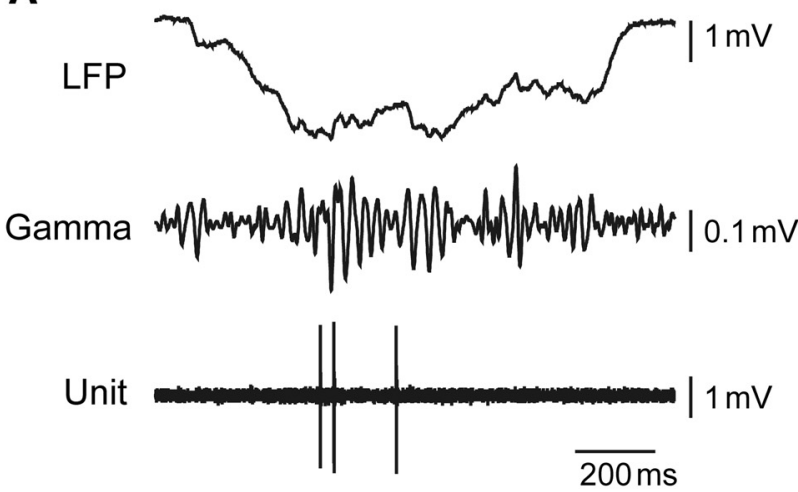

C
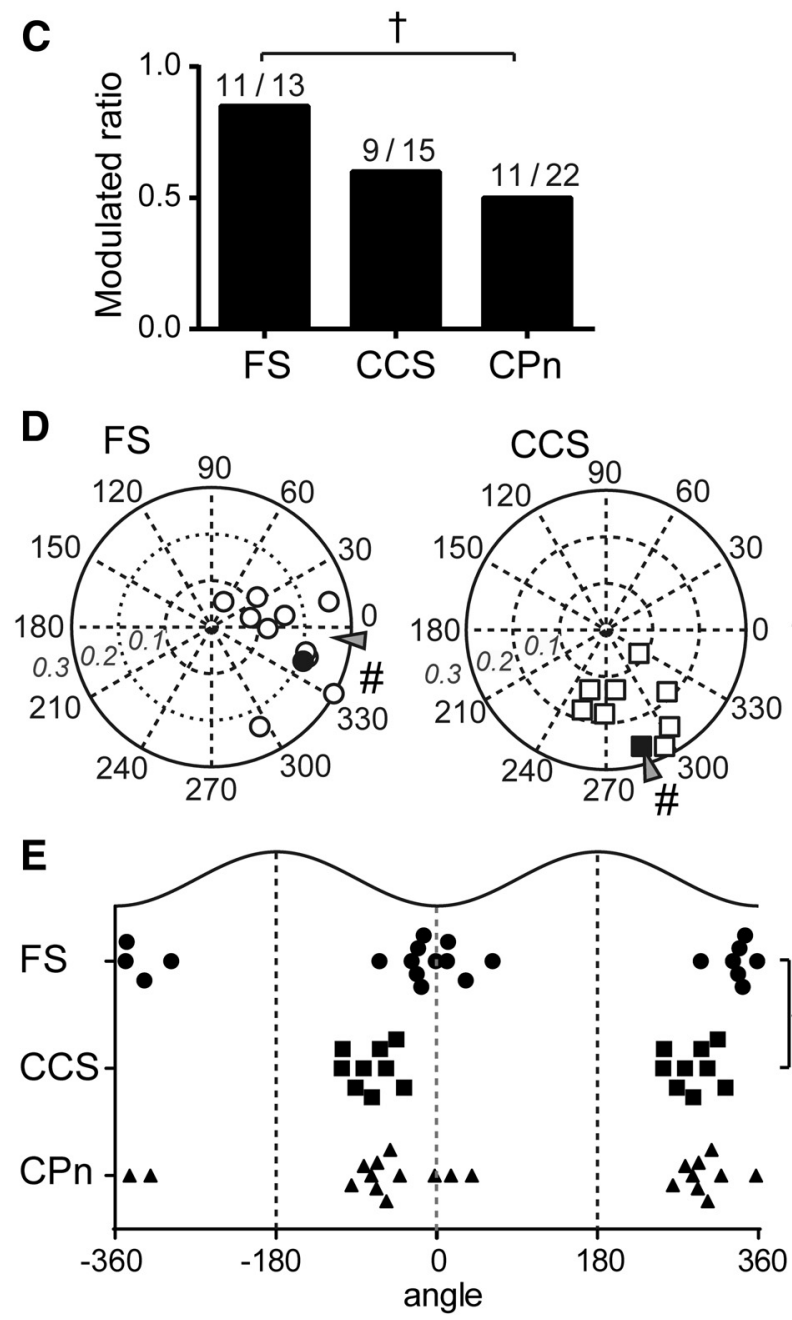
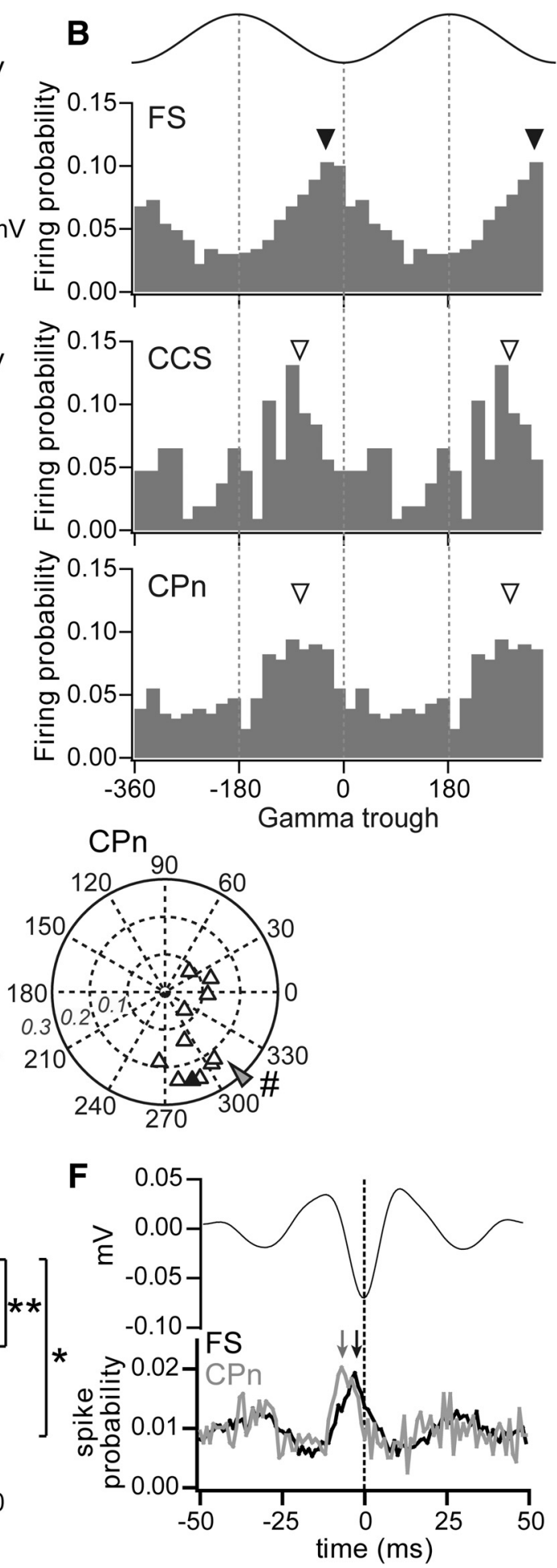

Figure 6. Gamma-wave modulation of L5 FS, CCS, and CPn cells. $\boldsymbol{A}$, Representative traces of the LFP, its gamma-wave component, and the unit activity of an FS cell. $\boldsymbol{B}$, Spike distributions of modulated FS, CCS, and CPn cells during gamma cycles. Arrowhead, Mean firing phase (filled, FS; open, CCS and CPn). Cycles are shown twice for clarity. C, Gamma wave-modulated cell ratios. FS cells were modulated more frequently than (Pn cells $(t p<0.05)$. $\boldsymbol{D}$, Angular concentration and firing phase of modulated $\mathrm{L} 5$ cells in the gamma wave. Gray italic number, Angular concentration; arrowhead, angle of mean vector; black marked circles indicate the neuron shown in $\boldsymbol{B}$. FS, CCS, and CPn cells had preferred firing phases (\#p $<0.01$, Hodges-Ajne test). $\boldsymbol{E}$, Firing phases of modulated FS, CCS, and CPn cells. Phase distributions of FS cells were different from those of CCS cells ( ${ }^{* *} p<0.01$; two-sample Watson-Williams test) and (Pn cells $\left({ }^{*} p<0.05\right)$. $\boldsymbol{F}$, Average of the gamma wave (top) and trough-triggered spike distributions of an FS cell (black) and a CPn cell (gray). Arrows indicate the peaks in each subtype (time difference, 4 ms).

both CCS and CPn cells $(p<0.05$; two-sample Watson-Williams test; Fig. 6E). Thus, CCS and CPn cells fired in more advanced phases of gamma oscillation than FS cells in circular analysis. Furthermore, pyramidal cells fired earlier, by several milliseconds, than FS cells in firing probability histograms triggered by gamma troughs (Fig. 6F; Hasenstaub et al., 2005). These observations suggest a firing order of L5 pyramidal and FS cells during gamma cycles. 

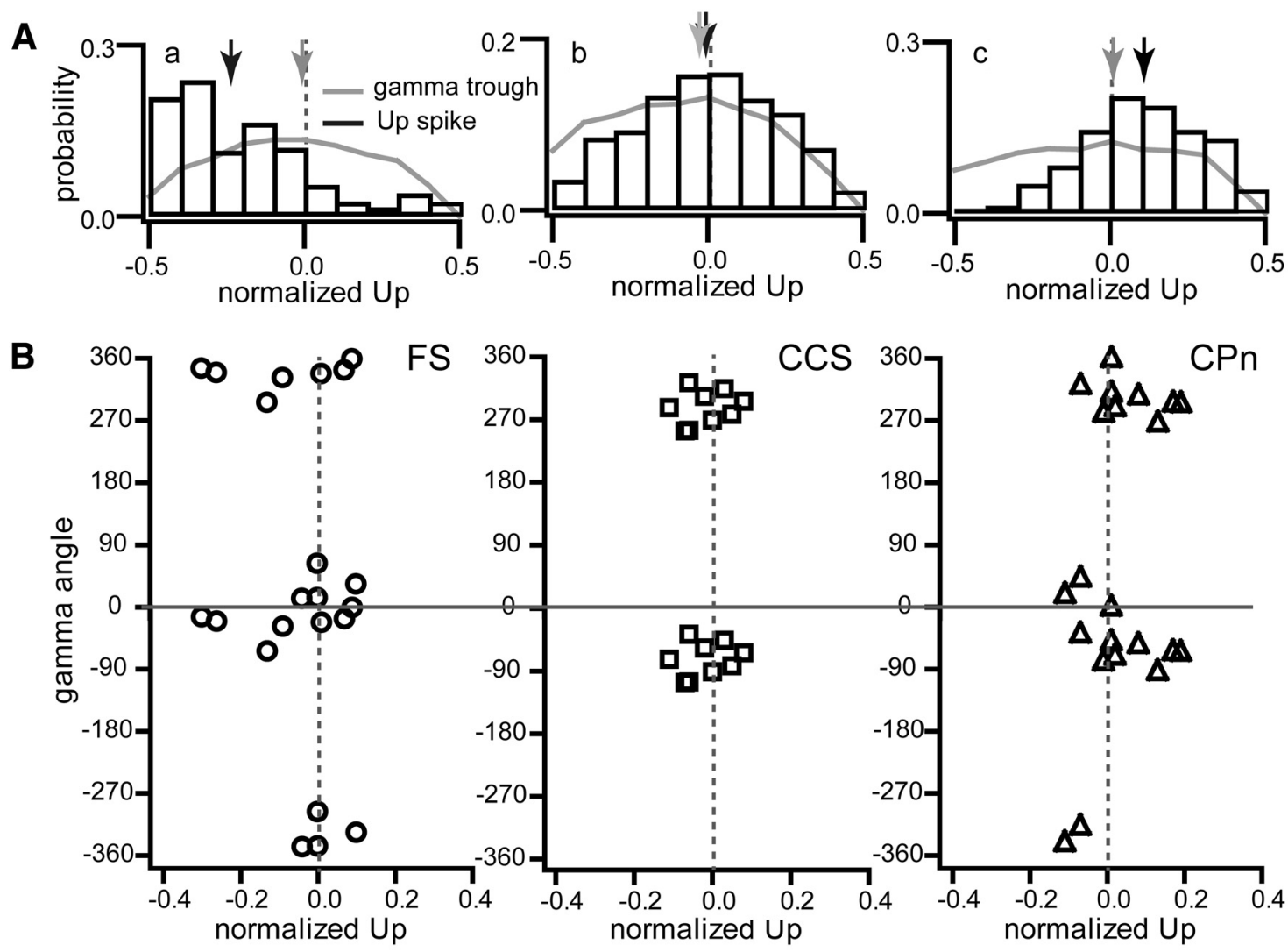

Figure 7. Gamma-wave modulation of cortical cells in Up-states. $A$, Gamma trough (gray line) and spike (white bar) distributions recorded at the same set of Up-states. Firing distributions of three FS cells were shown, as follows: $\boldsymbol{A} \boldsymbol{a}$, biased to early Up-states; $\boldsymbol{A} \boldsymbol{b}$, not biased to either early or late Up-states; $\boldsymbol{A} \boldsymbol{c}$, biased to late Up-states. Arrows, median value in gamma trough time (gray) and spike time (black). These indicate that the temporal firing preferences of individual FS cells were independent of the overall gamma trough distributions. $\boldsymbol{B}$, Relationship between Up firing time and gamma-modulated angle in L5 FS, CCS, and CPn cells. Cycles are shown twice for clarity.

Then we analyzed the relation of the Up firing time and gamma modulation in individual cells. The distribution of spikes was independent of that of the gamma trough recorded at the same set of Up-states (Fig. 7A). There was no clear relation between Up firing time and the gamma-modulated angle (Fig. $7 B$ ) or angular concentration in L5 cortical neuron subtypes.

\section{Cell subtype- and sublayer-specific firing characteristics of cortical neurons during DS- and Up-states}

The membrane potential of cortical neurons during the DS-state is depolarized to a level similar to that occurring in Up-states during SWs (Destexhe et al., 2007). However, we found that Upstates were larger in gamma power than DS-states $(p<0.05$ in all of five recordings; Mann-Whitney $U$ test). The gamma power ratio of DS- to Up-states was $0.50 \pm 0.14$. We therefore wondered whether the activity of cortical neuron subpopulations during DS-states is similar to that occurring during Up-states. To examine state-dependent firing characteristics, we continuously recorded unit activity in both SW- and DS-states for individual cells (Fig. 8A, top and bottom, respectively), and compared firing frequencies between Up-states and DS-states. Some neurons showed higher firing frequencies during Up-states than during DS-states (Up-active; Fig. 8A, left), but others had higher firing frequencies in DS-states (DS-active; Fig. 8A, right). FS cells exhibited higher firing frequencies than CCS and CPn cells in Upstates as well as in SW-states as a whole (Table 2; $p<0.01$, post hoc Dunn test). On the other hand, in DS-states, FS and CPn cells exhibited higher firing frequencies than CCS cells $(p<0.01$ and $p<0.05$, respectively).
To quantify firing frequency changes between Up- and DSstates, we calculated preference values for firing during Up-states and DS-states for each neuron (Fig. 8B; see Materials and Methods; values from -1 to $1 ; 1$, DS-only activity; -1 , Up-only activity). DS preference values were variable among FS cells, while L5a and L5b CCS cells preferentially fired during Up-states $(p<0.01$, one sample $t$ test); CPn cells did not exhibit preferences between Up- and DS-states. In L5b, Up-active cells were more numerous among CCS cells than among CPn cells (Fig. $8 B ; p<0.05$, post hoc Dunn test). To confirm the consistency of DS preferences, we analyzed two DS-states recorded at different times (10 cells). The DS preference was obtained for both the first and second DSstates. The two DS preferences for the same cells were similar (change from the first to second DS preference: $-0.02 \pm 0.29$, $p=0.82$ ), suggesting the reproducibility of the DS preference.

We found the firing differences among the cortical cell subtypes in Up-state firing times and their selectivity ( $\chi^{2}$ values) as well as firing changes from the SW Up-states to DS-states (DS preference; Fig. $8 C$ ). FS cells were larger in $\chi^{2}$ values and earlier in Up firing time. Most L2/3b FS cells exhibited early Up firing and had negative DS preferences (i.e., were Up-preferring; five of six cells). Between the pyramidal cell subtypes, CCS cells fired more in the early part of Up-states, whereas CPn cells fired more in the later part. $\chi^{2}$ values were larger in CPn cells than in CCS cells, and DS preferences were more negative (Up-preferring) in CCS cells. DS-active CPn cells were mostly late Up firing (15 of 17 cells). These confirmed that firing activity during Up-states and state preference of firing depend on the cell subtype and its sublayer. 

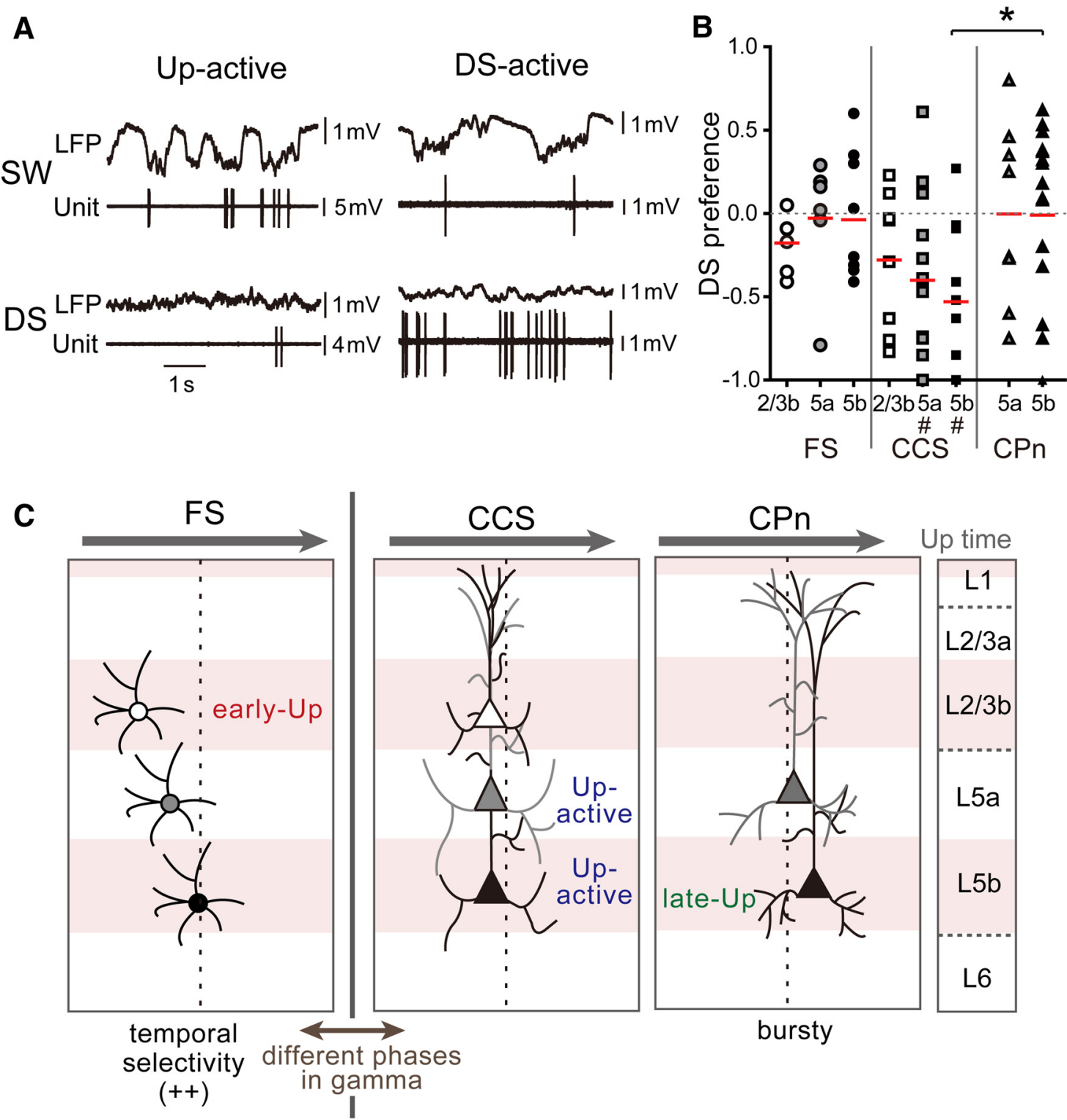

Figure 8. State dependency of firing and its relation to Up-state firing times. A, Firing frequency comparisons between Up-state activity in the SW-state (top) and during the DS-state (bottom). Examples of an Up-active cell with higher firing frequencies in Up-states than in DS-states (left) and a DS-active cell having higher firing frequencies in DS-states than in Up-states (right). $B, D S$ preferences of FS, CCS, and CPn cells in individual sublayers (1, firing only during DS-states, but not in Up-state; -1 , firing only in Up-state, but not in DS-states). In L5a and L5b CCS cells, most cells were Up-active (\#p $<0.01$, one-sample $t$ test). In L5b, Up-active cells were more numerous among CCS cells than among CPn cells $\left({ }^{*} p<0.05\right.$, post hoc Dunn test). Red line, Median. C, Firing sequences during Up-states according to neuron subtype and sublayer position. Pink color shows cortical sublayer with stronger VGluT2 immunoreactivity. FS cells showed prominent temporal firing selectivity during Up-states. Firing phase during gamma oscillations differed between L5 FS and L5 pyramidal cells, and CPn cells fired in a more burst-like manner.

Table 2. Firing frequency in each subtype

\begin{tabular}{|c|c|c|c|c|}
\hline & $\mathrm{FS}(n=21)$ & $\operatorname{cCS}(n=33)$ & $\mathrm{CPn}(n=26)$ & Dunn \\
\hline \multicolumn{5}{|l|}{ SW-state firing frequency $(\mathrm{Hz})$} \\
\hline Whole & $3.73 \pm 4.31(2.78)$ & $0.65 \pm 0.56(0.51)$ & $0.90 \pm 0.71 *(0.70)$ & $\mathrm{FS}>\mathrm{CCS}, \mathrm{CPn}$ \\
\hline Up-state & $5.30 \pm 5.97(3.95)$ & $1.27 \pm 0.74 \dagger(1.07)$ & $1.49 \pm 0.93(1.39)$ & $\mathrm{FS}>\mathrm{CCS}, \mathrm{CPn}$ \\
\hline DS-state firing frequency $(\mathrm{Hz})$ & $5.15 \pm 6.11(3.40)$ & $0.84 \pm 1.10(0.40)$ & $1.90 \pm 1.65(1.35)$ & $\mathrm{FS}, \mathrm{CPn}>\mathrm{CCS}$ \\
\hline
\end{tabular}

Data are reported as the mean \pm SD (median). $n$, Number of cells; Dunn, significant differences in post hoc Dunn multiple-comparisons test $(p<0.05)$.

${ }^{*} p<0.05,+p<0.01$, Mann-Whitney U test for SW- or Up-state versus DS-state firing frequency.

Firing patterns of L5 pyramidal projection cells

Next we compared physiological properties of L5 CCS and CPn cells directly, since L2/3 and L5 cells may have fundamentally different characteristics, even sharing the same external targets (Ueta et al., 2013). Between L5 pyramidal subtypes, CPn cells had narrower waveforms than CCS cells (Table 3). The interspike interval was shorter and the burst ratio was higher in CPn cells. CPn cells fired later than CCS cells in Up first spikes and in entire Up spike times of individual cells, and in total spike distributions. CPn cells had higher $\chi^{2}$ values than CCS cells, and more cells had 
Table 3. Comparisons among $L 5$ pyramidal cell subtypes

\begin{tabular}{|c|c|c|}
\hline & $\begin{array}{l}\mathrm{L} 5 \mathrm{CCS} \text { cells }(n=25) \\
{[\mathrm{L} 5 \mathrm{a}(n=15),} \\
\mathrm{L} 5 \mathrm{~b}(n=10)]\end{array}$ & $\begin{array}{l}\mathrm{L} 5 \mathrm{CPn} \text { cells }(n=26) \\
{[\mathrm{L} 5 \mathrm{a}(n=8),} \\
\mathrm{L} 5 \mathrm{~b}(n=18)]\end{array}$ \\
\hline \multicolumn{3}{|l|}{ Spike shape (ms) } \\
\hline First phase duration & $0.43 \pm 0.09$ & $0.41 \pm 0.11$ \\
\hline Second phase duration & $0.80 \pm 0.08$ & $0.74 \pm 0.11^{*}$ \\
\hline ISI during SW-state (ms) (<200 ms) & $41 \pm 14$ & $28 \pm 11 \dagger$ \\
\hline Burst ratio & $0.16 \pm 0.13$ & $0.35 \pm 0.20 \dagger$ \\
\hline $\begin{array}{l}\text { Up-state 1st spike time (median) } \\
\text { normalized ( }-0.5 \text { to } 0.5)\end{array}$ & $-0.16 \pm 0.10$ & $-0.04 \pm 0.14 \dagger$ \\
\hline $\begin{array}{l}\text { Up-state firing time (median) } \\
\text { normalized }(-0.5 \text { to } 0.5)\end{array}$ & $-0.03 \pm 0.08$ & $0.06 \pm 0.09 \dagger$ \\
\hline $\begin{array}{l}\text { Up-state early/late bias (cell } \\
\text { distribution) }\end{array}$ & n.s. & Late-biased $\neq$ \\
\hline$\chi^{2}$ value among 5 Up divisions & $11.2 \pm 8.3$ & $24 \pm 16.9 \dagger$ \\
\hline Cells with preferred Up time§ & $10(40 \%)$ & $21(81 \%) \uparrow$ \\
\hline Up-state firing frequency $(\mathrm{Hz})$ & $1.26 \pm 0.74$ & $1.49 \pm 0.93$ \\
\hline DS-state firing frequency $(\mathrm{Hz})$ & $0.74 \pm 0.98$ & $1.90 \pm 1.65 \dagger$ \\
\hline DS/Up preference $(-1$ to +1$)$ & $-0.45 \pm 0.48$ & $-0.01 \pm 0.52 \dagger$ \\
\hline DS/Up bias (cell distribution) & Up-biased $\neq$ & n.s. \\
\hline
\end{tabular}

Data are the reported as the mean \pm SD. Normalized time: -0.5 , Up start; 0 , Up center; -0.5 , Up end. DS/Up preference: -1 , Up-only activity; +1 , DS-only activity.

${ }^{*} p<0.05 ; \uparrow p<0.01$ (Mann-Whitney U test).

$\neq p<0.01$ (one-sample $t$ test); $\mathrm{n} . \mathrm{s} .$, no significance (one-sample $t$ test).

$\S$ Cells with $p<0.05$ from $\chi^{2}$ test for goodness of fit.

I $p<0.01$ ( $\chi^{2}$ test).

preferred firing times in CPn than in CCS cells. CCS cells preferred firing during Up-states compared with DS-states, but CPn cells were more diverse in their DS preference. These quantitative differences indicate that L5 CCS and CPn cells were distinct in intrinsic, circuit oscillation, and state-dependent firing characteristics (Table 3).

Previously, we analyzed firing characteristics of L5 corticothalamic (CTh) cells (Ushimaru et al., 2012). L5 CTh cells are a subpopulation of the CPn group in both L5a and L5b (Hirai et al., 2012; Ueta et al., 2014). Then we compared the firing pattern between L5 CPn and CTh cells. The CPn and CTh cells were similar in most parameters shown in Table 3 and in firing modulation by gamma oscillation (CTh cells: modulated ratio, 0.50 ; mean angle, $299^{\circ}$; angular concentration, $0.12 \pm 0.06$; unpublished data). However, they were different in total spike Up distribution and DS/Up preference. The total spike Up distribution (median) was 0.00 in CTh cells $(n=24$; sublayer unidentified), earlier than that in CPn cells, and later than that in CCS cells $(p<$ $0.01)$. The DS/Up preference was $-0.42 \pm 0.54$ in CTh cells smaller than CPn cells, but the cell distributions were biased neither to DS nor to Up preference in both CPn and CTh cells. These values suggest that L5 CTh cells share most firing characteristics with CPn cells, but are earlier in Up firing and more Up-active in the whole CPn group.

\section{Firing sequence of thalamic and cortical cell subtypes during up/down cycles}

The above observations revealed that cortical cells fire preferentially during Up-states, rather than during Down-states, and that the timing of activity during Up-states depends on neuron subtype (Fig. $8 C$ ). On the other hand, the activity of neurons in the Rt, ventrolateral (VL), and ventral anterior/ventromedial (VA/ VM) thalamic nuclei occurs during both Up- and Down-states (Ushimaru et al., 2012). Using previously obtained data on thalamic cell firing (Ushimaru et al., 2012), we compared spike-timing distributions during Up/Down cycles among cortical and thalamic cell subtypes. Many spikes in thalamic cells occurred during the Downstate, as follows: $16 \%$ in VA/VM cells; $12 \%$ in Rt cells; and $19 \%$ in VL cells, all more than in cortical cells (Fig. 9A).

Spike numbers were examined in individual periods (bin $=$ 0.05; normalized to 1 in each state) in a Down/Up sequence. Changes in spike number around the Up start (change per 0.1 bin width) were 0.09 in VA/VM cells, 0.03 in VL cells, 0.08 in Rt cells, 0.08 in FS cells, 0.02 in CCS cells, and 0.01 in CPn cells, indicating the active firing of thalamic and FS cells around the beginning of Up-states (Fig. 9B).

After the onset of Up-states, discharge of thalamic and cortical cells further increased. Among the cortical cells, FS and CCS cells increased faster than CPn cells as a whole; among the thalamic cells, VA/VM and Rt cells increased faster than VL cells (Fig. 9B). Notably, FS and CPn cells showed sublayer dependence in their firing distributions (Fig. 9C). These analyses confirm that firing activity increases in thalamic cells in advance of that in cortical cells during the Down-state-to-Up-state transition, and that the spike distribution during Up-states is dependent on the cortical and thalamic cell subtypes.

\section{Discussion}

To understand the temporal organization of cell type-specific activity during Up-states and DS-states, we analyzed neural activity in vivo during SW- and DS-states in CCS, CPn, and FS cells in L2/3b to L5b. In L5, some neurons in each cell type showed phase locking with gamma cycles, with FS neurons being out of phase with pyramidal cells (both CCS and CPn cells). At the transition from Down- to Up-states, we observed a distinct temporal order of activity. Thalamic neurons exhibited the earliest firing, which began during Down-states before the transition to Up-states. FS cells, especially those in L2/3b, exhibited the earliest Up-state activity, followed by activity in CCS cells, and finally in CPn cells. These results suggest that following thalamic input to the cortex, specific cortical output channels are activated in a temporally well organized sequence during Up-states. Further, our results show that the firing characteristics of L5 pyramidal cells during Up-states, and during DS-states, are differentiated according to projection subtypes.

\section{Neuron subtype-dependent firing time during the Up/Down cycle and its relation to connection directionality}

Shortly after Up-state initiation, as a whole, FS cells exhibited spike discharges that preceded the firing of CCS and CPn cells. CCS cells did not differ in their Up-state firing time specificity across sublayers, whereas FS and CPn cells in more superficial sublayers showed earlier Up-state firing times than did those in deeper sublayers. These firing time differences suggest that during Up-states, cortical neurons do not fire randomly but generate temporally organized firing sequences that may depend on the strength of their direct thalamocortical input and subcortical projection site.

While it has been assumed that the activation of L5 pyramidal cells initiates cortical Up-states (Sanchez-Vives and McCormick, 2000; Chauvette et al., 2010), thalamic inputs may play an important role in driving cortical Up-states (Contreras and Steriade, 1995; Rigas and Castro-Alamancos, 2007; Crunelli and Hughes, 2010), as thalamic activation can affect cortical states (Poulet et al., 2012). We previously reported that L5 corticothalamic cells fire only during Up-states, while some thalamic cells fire throughout Down/Up cycles (Ushimaru et al., 2012). It is especially noteworthy that some thalamic cells in the VA/VM and Rt nuclei selectively increase firing immediately before Up-state ini- 
A
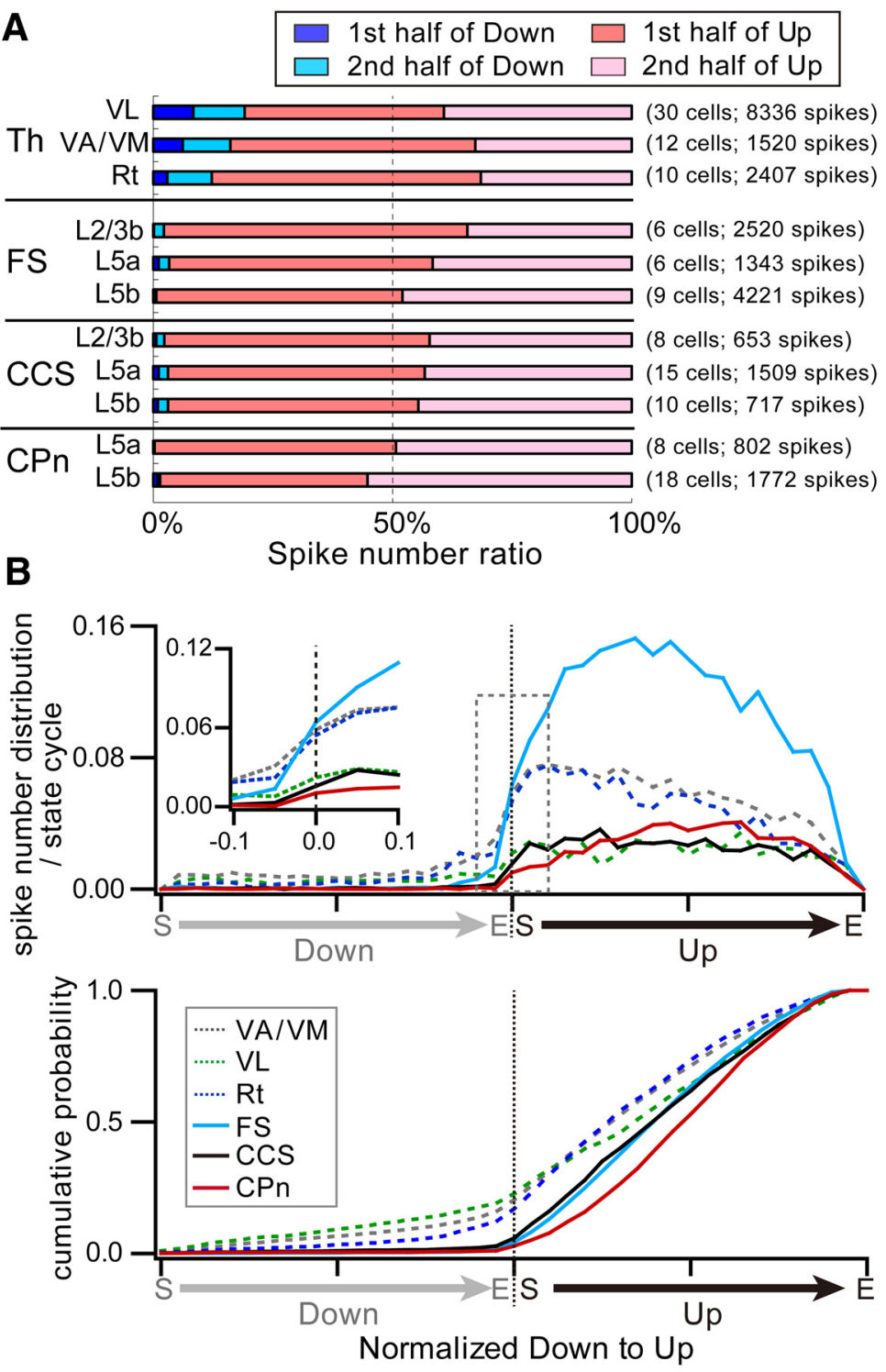

C

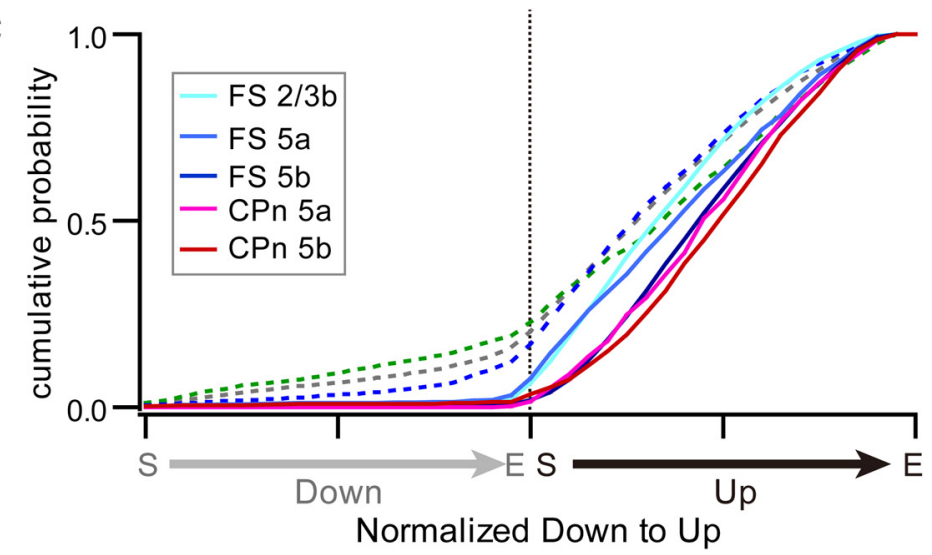

Figure 9. Firing time comparisons among the cortical and thalamic cells during whole Down/Up cycles. A, Spike distributions among four temporal divisions during Down/Up cycles. B, Spike distributions during a cycle from Down-start to Up-end in thalamic cells (VA/VM, VL, and Rt) and also in cortical cells (FS, CCS, and CPn). Individual Up- and Down-state durations were normalized to 1. S, Start of Down- or Up-state; E, end of Down- or Up-state. Top, Spike number density (bin width, 0.05). Inset, Enlargement around Up initiation (dotted area). Bottom, Cumulative spike probability. Number of Down/Up sequences was 3542 in FS cells ( $n=$ 21), 5619 in CCS cells $(n=33), 4584$ in CPn cells $(n=26), 6163$ in VA/VM cells $(n=30), 2578$ in VL cells $(n=12)$, and 2141 in Rt cells $(n=10)$. Data on thalamic cell firing were taken from our previous report (Ushimaru et al., 2012). C, Cumulative spike probability in $\mathrm{FS}$ and $\mathrm{CPn}$ cells in individual sublayers in addition to the thalamic cells. Dotted line shows the data from thalamiccells (in the same manner as in $\boldsymbol{B}$ ). tiation. Our present study demonstrates that, unlike thalamic neurons, cortical pyramidal and FS cells increase their activity only after the initiation of Up-states (Fig. 9). Recently, thalamic involvement in the cortical Up-state generation was established by pharmacological deafferentation experiments in the somatosensory and visual cortex (David et al., 2013; Lemieux et al., 2014). These results suggest that the neocortex itself can generate Upstates, but that thalamocortical excitatory inputs make a considerable contribution to Up-state initiation and the maintenance of regular Up/Down cycles. Thalamic neurons are diverse in their temporal selectivity of firing during $\mathrm{Up} /$ Down cycles in motor-related nuclei (Fig. 9B, C; Nakamura et al., 2014; Ushimaru et al., 2012) and in the somatosensory thalamus (Slézia et al., 2011). Correspondingly, the propagation of SWs is highly correlated in the specific thalamic nuclei and cortical areas (Sheroziya and Timofeev, 2014). To understand the regulatory mechanisms by which thalamocortical inputs initiate and maintain cortical Up-states, it will be necessary to determine the innervation patterns and short-term plasticity of thalamocortical inputs to the various subpopulations of cortical neurons (Cruikshank et al., 2012).

It is assumed that depolarization during Up-states is maintained by intracortical excitatory connections (Sanchez-Vives and McCormick, 2000; Hasenstaub et al., 2005), and that Up-states are predominantly generated in deeper layers (Amzica and Steriade, 1998; Chauvette et al., 2010). Indeed, optogenetic stimulation of infragranular neurons can generate slow oscillations in cortex (Beltramo et al., 2013). Here we found that the firing time of L5 pyramidal cells during Up-states was dependent on their projection site: the firing of CCS cells preceded that of CPn cells. This firing delay between subtypes likely corresponds to the unidirectional connectivity from CCS to CPn cells within L5 (Morishima and Kawaguchi, 2006; Kiritani et al., 2012). This temporal organization of activity among cortical neuron subtypes suggest that depolarization during the first half of the Up-state may be maintained by thalamocortical afferents and recurrent excitatory inputs from CCS cells, whereas depolarization during the second half of the Up-state may be maintained by increased $\mathrm{CPn}$ activity, supported by their intrinsic recurrent connectivity of higher reciprocity, facilitating synaptic transmission (Morishima et al., 2011). 


\section{Firing phase specificity of cortical cells during gamma oscillations}

It is reported that LFP negativity is associated with increased unit activities in the natural sleep and awake cat cortex (Destexhe et al., 1999). Consistent with this report, we observed the unit activities around the negativity of the gamma oscillation during Up-states. Gamma oscillation is thought to involve synchronous firing of a population of pyramidal neurons, followed by the transmission of the integrated information to downstream cells at the next processing stage (Womelsdorf et al., 2007; Shao et al., 2013). We did not observe differences in gamma firing phases between L5 CCS and CPn cells, suggesting the synchronous transfer of information from these two projection subtypes.

L5 CCS and CPn cells fired in a similar phase of the gamma wave, but FS cells demonstrated phase delay with respect to firing from pyramidal cells (Hasenstaub et al., 2005). This firing sequence may reflect mechanisms by which gamma oscillation is generated. In the frontal cortex, FS cells receive nonselective convergent inputs from CPn and CCS cells with similar probabilities. When FS cells are electrically coupled via gap junctions, they prefer to receive convergent excitatory inputs from common pyramidal cells (Otsuka and Kawaguchi, 2013). Pyramidal cells are often connected reciprocally with FS cells (Holmgren et al., 2003; Yoshimura and Callaway, 2005; Otsuka and Kawaguchi, 2009). Therefore, during individual cycles of gamma oscillation, the phase delay of FS neurons likely reflects the following scenario: populations of electrically coupled FS cells, driven by the synchronized output from presynaptic pyramidal cells, and the subsequent inhibition and rebound excitation of those pyramidal cell populations (Hasenstaub et al., 2005). It is reported that two different subtypes of PV-positive FS cells, axo-axonic and basket cells, fire with different timing in gamma oscillation (Massi et al., 2012). This suggests a further complex mechanism to control the gamma oscillation-related neural circuit.

\section{State dependence of cortical neuron firing}

Laminar differences in activity between the SW- and DS-states have been reported previously. In the auditory cortex, neurons in superficial layers tend to be SW-active, while neurons in deeper layers exhibit more heterogeneity in state dependency (Sakata and Harris, 2012). Our present results support this laminar specificity, in that neurons in L2/3b tended to be Up-active, while L5 neurons were more heterogeneous in their firing preferences (Fig. 8B).

We have reported that FS cells firing in the first half of the Up-state tend to be SW-active (Puig et al., 2008). Consistent with this, we confirmed that most L2/3b FS cells that fired in the first half of the Up-states exhibited Up-active firing patterns. Furthermore, Up-state firing time preferences, and state dependences, were characteristic of CCS and CPn cells. CCS cells were more likely to be Up-active than CPn neurons. These Up-active firing cells might correspond to the "Wake-silent" pyramidal cells (Rudolph et al., 2007). During DS-states, the spontaneous activity of CPn cells was higher than that of CCS cells in L5. It is possible that increases in acetylcholine concentration during DS-states may selectively promote sustained activity in CPn rather than CCS neurons (Dembrow et al., 2010; Wester and Contreras, 2013).

\section{Function of projection-dependent firing sequences during Up-states}

In L5, CCS cells transmit their activity unidirectionally to CPn cells (Morishima et al., 2011; Morita et al., 2012). In addition to the striatum, CCS cells project to area 36 of the perirhinal cortex
(Hirai et al., 2012; Ueta et al., 2014). Area 36 is connected to the hippocampus through area 35 (Burwell and Amaral, 1998) and in turn projects to L2/3b of the frontal cortex (Y. Ueta and Y. Kawaguchi, unpublished observations). Thus, during the first half of Up-states, CCS cells and the perirhinal cortex may excite each other, with L2/3 dendrites of CCS cells receiving memory information from the hippocampus. During the second half of Up-states, reciprocal excitation of CPn cells, including corticothalamic cells (Hirai et al., 2012), may hold the CCS-acquired information on-line for a time. It has been proposed that synaptic connections are restructured during SWs (Louie and Wilson, 2001; Euston et al., 2007), suggesting that the fronto-perirhinal corticocortical loop may be reorganized during the first half of Up-states, whereas the frontal corticothalamic loop may be remodeled during the second half of Up-states.

In this study, we found that two different subcortical projection cells, L5 CCS and CPn cells, differ in their temporal firing preferences during Up-states, in addition to their intrinsic electrical properties, connection patterns, and synaptic transmission characteristics, as previously reported (Morishima and Kawaguchi, 2006; Morishima et al., 2011). Considered from the external projection sites, CCS cells might be related more to the declarative memory, whereas CPn cells might be related more to the procedural memory. But both subtypes directly project to the striatum. Therefore, we propose the existence of phasedependent information processing within Up-states in both the frontal cortex and striatum, using the temporally organized CCS-CPn system.

\section{References}

Amzica F, Steriade M (1998) Cellular substrates and laminar profile of sleep K-complex. Neuroscience 82:671-686. Medline

Beltramo R, D’Urso G, Dal Maschio M, Farisello P, Bovetti S, Clovis Y, Lassi G, Tucci V, De Pietri Tonelli D, Fellin T (2013) Layer-specific excitatory circuits differentially control recurrent network dynamics in the neocortex. Nat Neurosci 16:227-234. CrossRef Medline

Burwell RD, Amaral DG (1998) Perirhinal and postrhinal cortices of the rat: interconnectivity and connections with the entorhinal cortex. J Comp Neurol 391:293-321. CrossRef Medline

Buzsáki G, Draguhn A (2004) Neuronal oscillations in cortical networks. Science 304:1926-1929. CrossRef Medline

Chauvette S, Volgushev M, Timofeev I (2010) Origin of active states in local neocortical networks during slow sleep oscillation. Cereb Cortex 20: 2660-2674. CrossRef Medline

Contreras D, Steriade M (1995) Cellular basis of EEG slow rhythms: a study of dynamic corticothalamic relationships. J Neurosci 15:604-622. Medline

Cowan RL, Wilson CJ (1994) Spontaneous firing patterns and axonal projections of single corticostriatal neurons in the rat medial agranular cortex. J Neurophysiol 71:17-32. Medline

Cruikshank SJ, Ahmed OJ, Stevens TR, Patrick SL, Gonzalez AN, Elmaleh M, Connors BW (2012) Thalamic control of layer 1 circuits in prefrontal cortex. J Neurosci 32:17813-17823. CrossRef Medline

Crunelli V, Hughes SW (2010) The slow $(<1 \mathrm{~Hz})$ rhythm of non-REM sleep: a dialogue between three cardinal oscillators. Nat Neurosci 13:9-17. CrossRef Medline

David F, Schmiedt JT, Taylor HL, Orban G, Di Giovanni G, Uebele VN, Renger JJ, Lambert RC, Leresche N, Crunelli V (2013) Essential thalamic contribution to slow waves of natural sleep. J Neurosci 33:1959919610. CrossRef Medline

Dembrow NC, Chitwood RA, Johnston D (2010) Projection-specific neuromodulation of medial prefrontal cortex neurons. J Neurosci 30:1692216937. CrossRef Medline

Destexhe A, Contreras D, Steriade M (1999) Spatiotemporal analysis of local field potentials and unit discharges in cat cerebral cortex during natural wake and sleep states. J Neurosci 19:4595-4608. Medline

Destexhe A, Hughes SW, Rudolph M, Crunelli V (2007) Are corticotha- 
lamic 'up' states fragments of wakefulness? Trends Neurosci 30:334-342. CrossRef Medline

Euston DR, Tatsuno M, McNaughton BL (2007) Fast-forward playback of recent memory sequences in prefrontal cortex during sleep. Science 318 : 1147-1150. CrossRef Medline

Hasenstaub A, Shu Y, Haider B, Kraushaar U, Duque A, McCormick DA (2005) Inhibitory postsynaptic potentials carry synchronized frequency information in active cortical networks. Neuron 47:423-435. CrossRef Medline

Hirai Y, Morishima M, Karube F, Kawaguchi Y (2012) Specialized cortical subnetworks differentially connect frontal cortex to parahippocampal areas. J Neurosci 32:1898-1913. CrossRef Medline

Holmgren C, Harkany T, Svennenfors B, Zilberter Y (2003) Pyramidal cell communication within local networks in layer $2 / 3$ of rat neocortex. J Physiol 551:139-153. CrossRef Medline

Kiritani T, Wickersham IR, Seung HS, Shepherd GM (2012) Hierarchical connectivity and connection-specific dynamics in the corticospinalcorticostriatal microcircuit in mouse motor cortex. J Neurosci 32:49925001. CrossRef Medline

Lei W, Jiao Y, Del Mar N, Reiner A (2004) Evidence for differential cortical input to direct pathway versus indirect pathway striatal projection neurons in rats. J Neurosci 24:8289-8299. CrossRef Medline

Lemieux M, Chen JY, Lonjers P, Bazhenov M, Timofeev I (2014) The impact of cortical deafferentation on the neocortical slow oscillation. J Neurosci 34:5689-5703. CrossRef Medline

Lőrincz ML, Gunner D, Bao Y, Connelly WM, Isaac JT, Hughes SW, Crunelli $\mathrm{V}$ (2015) A distinct class of slow $(\sim 0.2-2 \mathrm{~Hz})$ intrinsically bursting layer 5 pyramidal neurons determines UP/DOWN state dynamics in the neocortex. J Neurosci 35:5442-5458. CrossRef Medline

Louie K, Wilson MA (2001) Temporally structured replay of awake hippocampal ensemble activity during rapid eye movement sleep. Neuron 29:145-156. CrossRef Medline

Massi L, Lagler M, Hartwich K, Borhegyi Z, Somogyi P, Klausberger T (2012) Temporal dynamics of parvalbumin-expressing axo-axonic and basket cells in the rat medial prefrontal cortex in vivo. J Neurosci 32:1649616502. CrossRef Medline

Mena-Segovia J, Sims HM, Magill PJ, Bolam JP (2008) Cholinergic brainstem neurons modulate cortical gamma activity during slow oscillations. J Physiol 586:2947-2960. CrossRef Medline

Metherate R, Ashe JH (1993) Ionic flux contributions to neocortical slow waves and nucleus basalis-mediated activation: whole-cell recordings in vivo. J Neurosci 13:5312-5323. Medline

Morishima M, Kawaguchi Y (2006) Recurrent connection patterns of corticostriatal pyramidal cells in frontal cortex. J Neurosci 26:4394-4405. CrossRef Medline

Morishima M, Morita K, Kubota Y, Kawaguchi Y (2011) Highly differentiated projection-specific cortical subnetworks. J Neurosci 31:1038010391. CrossRef Medline

Morita K, Morishima M, Sakai K, Kawaguchi Y (2012) Reinforcement learning: computing the temporal difference of values via distinct corticostriatal pathways. Trends Neurosci 35:457-467. CrossRef Medline

Mukovski M, Chauvette S, Timofeev I, Volgushev M (2007) Detection of active and silent states in neocortical neurons from the field potential signal during slow-wave sleep. Cereb Cortex 17:400-414. CrossRef Medline

Nakamura KC, Sharott A, Magill PJ (2014) Temporal coupling with cortex distinguishes spontaneous neuronal activities in identified basal gangliarecipient and cerebellar-recipient zones of the motor thalamus. Cereb Cortex 24:81-97. CrossRef Medline

Otsuka T, Kawaguchi Y (2009) Cortical inhibitory cell types differentially form intralaminar and interlaminar subnetworks with excitatory neurons. J Neurosci 29:10533-10540. CrossRef Medline

Otsuka T, Kawaguchi Y (2013) Common excitatory synaptic inputs to electrically connected cortical fast-spiking cell networks. J Neurophysiol 110: 795-806. CrossRef Medline

Pinault D (1996) A novel single-cell staining procedure performed in vivo under electrophysiological control: morpho-functional features of juxtacellularly labeled thalamic cells and other central neurons with biocytin or Neurobiotin. J Neurosci Methods 65:113-136. CrossRef Medline
Poulet JF, Fernandez LM, Crochet S, Petersen CC (2012) Thalamic control of cortical states. Nat Neurosci 15:370-372. CrossRef Medline

Puig MV, Ushimaru M, Kawaguchi Y (2008) Two distinct activity patterns of fast-spiking interneurons during neocortical Up-states. Proc Natl Acad Sci U S A 105:8428-8433. CrossRef Medline

Rigas P, Castro-Alamancos MA (2007) Thalamocortical Up-states: differential effects of intrinsic and extrinsic cortical inputs on persistent activity. J Neurosci 27:4261-4272. CrossRef Medline

Rudolph M, Pospischil M, Timofeev I, Destexhe A (2007) Inhibition determines membrane potential dynamics and controls action potential generation in awake and sleeping cat cortex. J Neurosci 27:5280-5290. CrossRef Medline

Sakata S, Harris KD (2012) Laminar-dependent effects of cortical state on auditory cortical spontaneous activity. Front Neural Circuits 6:109. CrossRef Medline

Sanchez-Vives MV, McCormick DA (2000) Cellular and network mechanisms of rhythmic recurrent activity in neocortex. Nat Neurosci 3:10271034. CrossRef Medline

Shao YR, Isett BR, Miyashita T, Chung J, Pourzia O, Gasperini RJ, Feldman DE (2013) Plasticity of recurrent 12/3 inhibition and gamma oscillations by whisker experience. Neuron 80:210-222. CrossRef Medline

Sheroziya M, Timofeev I (2014) Global intracellular slow-wave dynamics of the thalamocortical system. J Neurosci 34:8875-8893. CrossRef Medline

Shigematsu N, Ueta Y, Mohamed AA, Hatada S, Fukuda T, Kubota Y, Kawaguchi Y (2015) Selective thalamic innervation of rat frontal cortical neurons. Cereb Cortex. Advance online publication. Accessed 3 June 2015. DOI:10.1093/cercor/bhv124. CrossRef Medline

Slézia A, Hangya B, Ulbert I, Acsády L (2011) Phase advancement and nucleus-specific timing of thalamocortical activity during slow cortical oscillation. J Neurosci 31:607-617. CrossRef Medline

Sohal VS, Zhang F, Yizhar O, Deisseroth K (2009) Parvalbumin neurons and gamma rhythms enhance cortical circuit performance. Nature 459: 698-702. CrossRef Medline

Steriade M (2006) Grouping of brain rhythms in corticothalamic systems. Neuroscience 137:1087-1106. CrossRef Medline

Steriade M, Nuñez A, Amzica F (1993) A novel slow ( $<1 \mathrm{~Hz}$ ) oscillation of neocortical neurons in vivo: depolarizing and hyperpolarizing components. J Neurosci 13:3252-3265. Medline

Ueta Y, Hirai Y, Otsuka T, Kawaguchi Y (2013) Direction- and distancedependent interareal connectivity of pyramidal cell subpopulations in the rat frontal cortex. Front Neural Circuits 7:164. CrossRef Medline

Ueta Y, Otsuka T, Morishima M, Ushimaru M, Kawaguchi Y (2014) Multiple layer 5 pyramidal cell subtypes relay cortical feedback from secondary to primary motor areas in rats. Cereb Cortex 24:2362-2376. CrossRef Medline

Ushimaru M, Ueta Y, Kawaguchi Y (2012) Differentiated participation of thalamocortical subnetworks in slow/spindle waves and desynchronization. J Neurosci 32:1730-1746. CrossRef Medline

Valencia M, Artieda J, Bolam JP, Mena-Segovia J (2013) Dynamic interaction of spindles and gamma activity during cortical slow oscillations and its modulation by subcortical afferents. PLoS One 8:e67540. CrossRef Medline

Volgushev M, Chauvette S, Mukovski M, Timofeev I (2006) Precise long-range synchronization of activity and silence in neocortical neurons during slowwave oscillations [corrected]. J Neurosci 26:5665-5672. CrossRef Medline

Wester JC, Contreras D (2013) Differential modulation of spontaneous and evoked thalamocortical network activity by acetylcholine level in vitro. J Neurosci 33:17951-17966. CrossRef Medline

Wilson CJ (1987) Morphology and synaptic connections of crossed corticostriatal neurons in the rat. J Comp Neurol 263:567-580. CrossRef Medline

Womelsdorf T, Schoffelen JM, Oostenveld R, Singer W, Desimone R, Engel AK, Fries P (2007) Modulation of neuronal interactions through neuronal synchronization. Science 316:1609-1612. CrossRef Medline

Yoshimura Y, Callaway EM (2005) Fine-scale specificity of cortical networks depends on inhibitory cell type and connectivity. Nat Neurosci 8:1552-1559. CrossRef Medline 